\title{
Antecedents of Trust in Electronic-Service Providers: Results from a Meta-Analysis
}

\author{
Jian Mou \\ Department of Information Systems \\ University of the Witwatersrand, Johannesburg \\ jian.mou@wits.ac.za \\ Jason Cohen \\ Department of Information Systems \\ University of the Witwatersrand, Johannesburg \\ jason.cohen@wits.ac.za
}

\begin{abstract}
Consumers' trust beliefs are considered amongst the most important psychological states influencing their online behavior. Understanding the antecedents of consumer trust is thus of both academic and practical interest. Research into these antecedents has however been disconnected, and has not been integrated to provide an answer as to which are the most significant antecedents of trust. To address this problem, we synthesized the antecedents of trust in e-service through a meta-analysis of 67 previously published studies. The findings showed that structural assurance (STA), reputation (REP), perceived usefulness (PU), system quality (SYQ) and service quality (SEQ) demonstrate the strongest effect sizes on trust. Furthermore, vendor size (SIZ) and privacy protection (PRC) also affect trust, but to a lesser degree. Moreover, we found trust can be usefully integrated with constructs from the TAM and IS Success models. We considered explanations for identified heterogeneity in effect sizes through moderator analysis. We found that cultural context of the study almost moderated all the effect sizes, and certain effect sizes were also moderated by factors such as the type of eservice and the use of student samples. Results are important to guiding future e-services research and helping practitioners to better build e-service promotion strategy.
\end{abstract}

Keywords: Trust, Meta-Analysis, Trust Building, Trust Antecedents, E-Service, Electronic Service 


\section{Introduction}

With the development of the Internet and mobile device technology, the delivery of services has changed from face-to-face to electronic exchange or e-service. E-service allows consumer to interact with service providers without the constraints of time and space (Beldad et al., 2010). Unfortunately, uncertainties still characterize the use of eservices and varying degrees of consumer adoption and engagement in the use of eservices has been noted (Featherman and Pavlou, 2003; Kim et al., 2009a). The uncertainties arise because the technology mediated nature of e-service creates a temporal and physical distance between consumer and provider, which can lead to opportunistic behaviors (Gefen et al., 2003a; Dinev and Hart, 2006). These uncertainties result in increased consumer perceptions of risk and elevate the need for trust in electronic exchange relationships (Pavlou, 2003). Consumers' trust beliefs have therefore been considered amongst the most important psychological states influencing their online behaviors (Pavlou and Gefen, 2002; Pavlou, 2003; Kim et al., 2008). Past works have associated trust with adoption and use in e-service contexts such as e-commerce/e-shopping (Jarvenpaa et al., 2000; Corbitt et al., 2003; Gefen et al., 2003a; Pavlou, 2003; Teo and Liu, 2007; Kim et al., 2008; Zhu et al., 2011), e-banking (Yousafzai et al., 2009; Luo et al., 2010), online health care services (Zahedi and Song, 2008; Egea and Gonzalez, 2011; Mou and Cohen, 2014), online legal services (Cho, 2006), mobile payment services (Lu et al., 2011) and e-government (Horst et al., 2007; Bélanger and Carter, 2008).

Without trust, consumers are less likely to engage in e-service usage and therefore the economic potential of e-services is lessened (Walczuch and Lundgren, 2004). Moreover, the potential benefits of non-commercial eservices, such as e-government or consumer e-health services, are also likely to go unrealized (Bélanger and Carter, 2008; Yi et al., 2013).
Given its importance to so many contexts, researchers have unsurprisingly turned their attention to examining the antecedents of consumers' trust beliefs (e.g., McKnight et al., 2002; Gefen et al., 2003a; Kim et al., 2008). These studies have highlighted the importance of antecedents such as perceived institution size and market share of the online vendor (Jarvenpaa et al., 2000; Teo and Liu, 2007), perceived vendor or brand reputation (Jarvenpaa et al., 2000; Pavlou, 2003; Teo and Liu, 2007; Kim et al., 2008), the role of structural assurances (Chandra et al., 2010; Zhu et al., 2011), and even individual factors such as propensity to trust (Pavlou and Gefen, 2004; Nicolaou and McKnight, 2006; Teo and Liu, 2007; Kim et al., 2008). However, these efforts have been disconnected and have not been integrated so as to provide an answer as to which are the most important antecedents of trust. Previous studies summarizing the antecedents of trust are mostly literature reviews (e.g., Grabner-Kräuter and Kaluscha, 2003; Walczuch and Lundgren, 2004; Wareham et al., 2005; Beatty et al., 2011), which have not provided aggregate effect sizes so as to determine the most significant factors. Where meta-analytic studies into trust have been carried out, those have mostly focused on the context of e-commerce (e.g., He, 2011), rather than the broader domain of e-services that include both commercial and noncommercial contexts. Moreover, they have not addressed the contradictory findings regarding the antecedents of trust. For example, the effects of consumer familiarity with the online vendor has been found an important antecedent of trust in one study (Gefen, 2000; Gefen et al., 2003a) whilst not significant in another (Cho et al., 2007). Moreover, privacy concern was significantly correlated with trust in Chiu et al. (2009) but not in Bansal et al. (2010). Explanations for such variations in previously reported effect sizes have not been adequately examined. Thus existing efforts fail to provide us insights into those antecedents that are universal across e-service contexts and those that might be relatively more or less 
important depending on the type of eservice. Other potential moderators such as culture and population under study might impact the relative effects of previously examined antecedents of trust.

The purpose of this study is therefore to contribute to the e-service literature by comprehensively identifying and classifying the antecedents of trust in e-services, and thereafter identify which antecedents are important to form consumer trust. We adopt a broad definition of e-services so as to include both commercial (e.g., e-shopping and e-banking) and non-commercial (e.g., e-health and e-government) e-services. Because there may be sufficient differences in correlations across studies, it is also important to determine the extent to which these effects are moderated by factors such as culture, type of e-service and sampling strategy. Specifically, we pose the following research questions:

RQ1: What are the key antecedents of trust in the e-service context?

RQ2: To what extent are these antecedents moderated by factors such as culture, type of e-service, and sampling strategy?

To answer these questions this study adopts a meta-analytic approach to determine bare-bone effect sizes (corrected sampling error), true-score effect sizes (corrected measurement error), and homogeneity tests for determining potential for moderating effects.

Our study has implications for both research and practice in a number of ways. First, our study classifies the antecedents of trust into vendor and institution-based; technologicalbased; knowledge-based and consumerbased which can provide a useful framework for future research. Second, our study can help researchers better understand which antecedents are important to form consumer trust in the eservice context. By comparing the intensity of effect sizes and moderation effects, our results will also reveal important factors on which e-service providers may wish to concentrate their trust building efforts. Online providers will thus be better positioned to establish their online service offerings and build better e-service promotion strategies across different context and consumer cultures.

In the next section, we discuss e-services and prior research on trust in e-services. We then develop a classification of the antecedents of trust and present a research model that underpins our meta-analytic investigation. Next, the methodology and approach to the meta-analysis are outlined. At last, results are presented and the paper concludes with a discussion and implications.

\section{Literature Review and Research Model}

\section{E-service}

de Ruyter et al. (2001) define e-service as "an interactive content-centered and Internet-based customer service". Later, Rowley (2006) defined e-service as any "deeds, efforts or performances whose delivery is mediated by information technology (including the Web, information kiosks and mobile devices)". E-services not only facilitate provider-to-consumer interaction but also offer lower-cost of transaction and increase consumer choice (de Ruyter et al., 2001; Rowley, 2006; Teo and Liu, 2007). In this study, e-service is thus defined as any service whose delivery is enabled by Internet technologies, and incorporates a large self-service component i.e. where consumers co-produce the service outcome through their interaction with these technologies. Under this definition, e-services include forms of business-to-consumer e-commerce such as e-shopping, e-banking services (including both mobile and Internet banking), e-health services (e.g., online health information), egovernment services such as online tax, online legal services, and mobile payment services amongst others.

The emergence of e-services brings a number of benefits to e-service providers 
e.g., broadening their market reach and lowering of entry barriers to new markets (Lu, 2001). For consumers, e-services offer convenience, lower cost of transacting and accessibility (de Ruyter et al., 2001; Boyer et al., 2002). Despite these various benefits, e-services are also associated with numerous uncertainties. The virtual environments within which e-services occur are prone to security and encryption problems (Vassilakis et al., 2005). Moreover, the technology mediated nature of e-service creates a temporal and physical distance between the service consumer and the service provider, which can lead to opportunistic behaviors such as misrepresentation, unfair pricing, conveying inaccurate information and violations of privacy (Gefen et al., 2003b; Dinev and Hart, 2006; Kim et al., 2008). Consideration of these uncertainties has led past research to examine trust as an important factor facilitating the adoption of e-services by consumers (de Ruyter et al., 2001; Mou and Cohen, 2014).

\section{Trust}

Trust plays an important role in exchange relationships between organizations and their customers (Corbitt et al., 2003; Teo and Liu, 2007). Rotter (1967) defines interpersonal trust as "the belief that a party's word or promise is reliable and a party will fulfil his/her obligations in an exchange relationship". In the online context, researches have distinguished between trust in the website interface (e.g., Dinev and Hart, 2006; Liao et al., 2011) and trust in the e-service provider (e.g., Gefen, 2002; Pavlou and Gefen, 2004; Nicolaou and McKnight, 2006; Kim et al., 2008, 2009a). Trust in the website interface implies Internet websites are a secure and reliable environment from which to access the service and exchange information with others (Liao et al., 2011). Trust in the eservice provider is defined as the consumer's belief in the integrity, ability and benevolence of the vendor (Rotter, 1967; Morgan and Hunt, 1994; Bhattacherjee, 2002; Pavlou and Gefen, 2002) and their willingness to be vulnerable to actions taken by the vendor based on their feelings of confidence and assurance (Gefen, 2000). If e-vendors are not considered trustworthy, they will lose their customers (Zhu et al., 2011). Past studies indicate that trust in the e-service provider is the more important (proximal) determinant of consumer acceptance of an e-service than trust in the website platform (Mou and Cohen, 2013). Consequently, we focus here on the antecedent of consumers' trust beliefs in the e-service provider.

\section{Antecedents of Trust in e-Service Provider}

Past researchers have classified the antecedents of trust in a number of ways. Unfortunately, there is no generally agreed classification framework. However, there are some common categories that can be discerned which input into our framework. Initially, Gefen et al. (2003a) classified trust antecedents as calculative-based, institution-based (structural assurances and situational normality), and knowledge-based (familiarity). Later, Kim et al. (2008) classified the antecedents of trust in the ecommerce context as cognition-based, affect-based, experience-based and personality-oriented. He (2011) systematically reviewed the antecedents of trust in e-commerce and classified them as: personal characteristics-based, knowledgebased, deterrence-based, social influencebased, technological attributes-based, vendor image-based and institution-based.

Common to all these previous classifications are a focus on the inclusion of vendor related factors such as reputation and vendor size, technology related factors such as perceived usefulness and perceived ease of use, individual consumer such as disposition to trust, and knowledge or experience related factors such as familiarity. Consequently, we classify the identified antecedents into four categories, which we label as vendor and institutionbased antecedents, technological-based antecedents, knowledge-based antecedents, 
and consumer characteristics-based.

Based on above discussion, the four categories representing the antecedents of trust that will be investigated in this meta- analysis are presented in Figure 1 together with the potential moderators of their links with trust. These are discussed next.

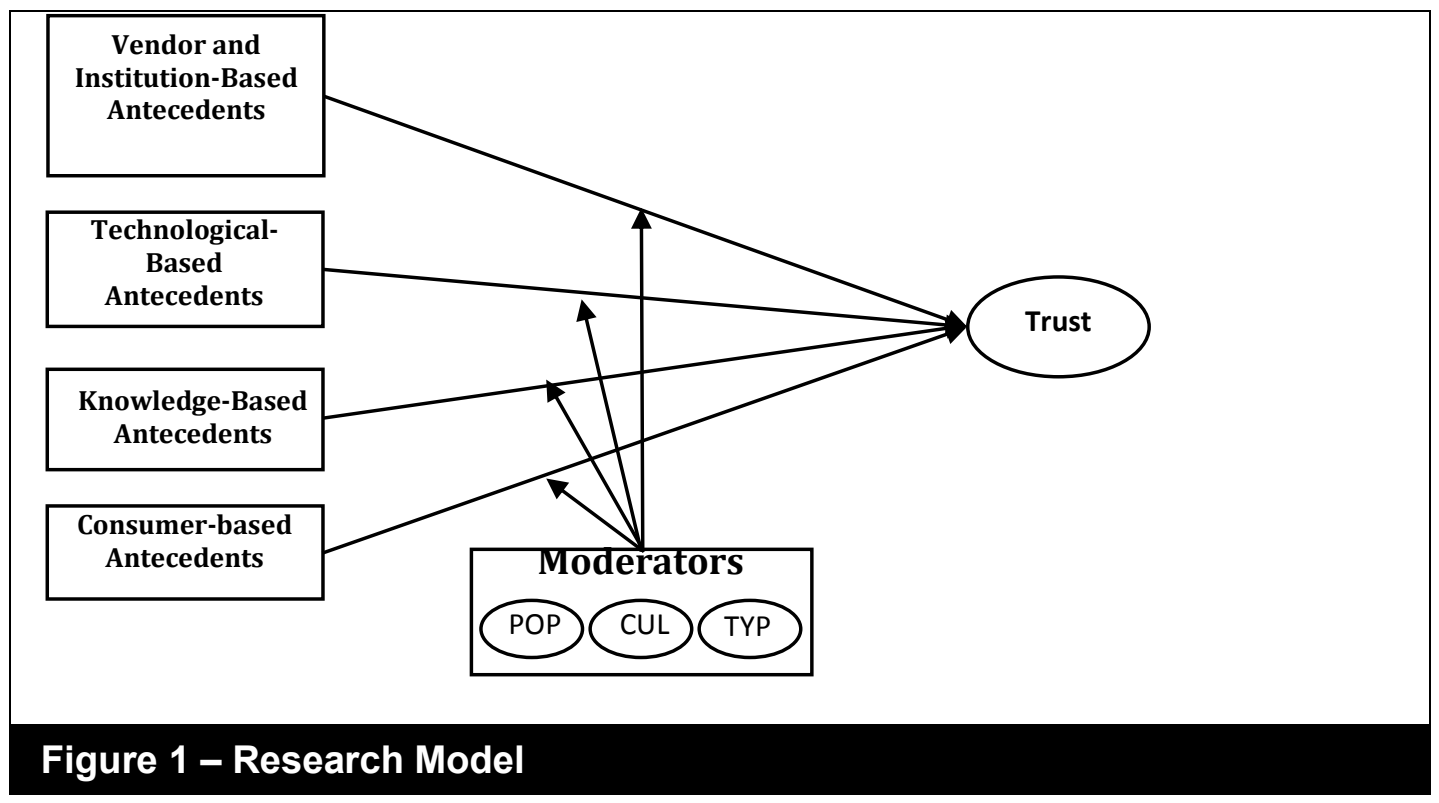

Notes: POP: Population under study; CUL: Culture; TYP: Type of e-service.

\section{Vendor and Institution-Based Antecedents}

In the field of e-commerce, past works have identified vendor and institution-based factors as important determinants of trust for new consumers (He, 2011; Koufaris and Hampton-Sosa, 2004). Amongst these, vendor size, vendor reputation, and vendor's ability for customization, along with institutional influences such as perceived privacy protection, perceived security protection, perceived structural assurances, situational normality, service quality and perceived risk have been subject to the most attention. Our vendor and institutionbased antecedents can be traced to various theoretical underpinnings. A set of vendor and institution-based antecedents (e.g., reputation, structural assurance) have been suggest by economic and marketing literature. Transference theory of trust suggests that trustors will draw on other sources (e.g., words and actions of other people in the market) as a basis for inferring trustworthiness of a party with whom they have no direct experience (Doney and Cannon, 1997). In marketing settings, perceived online firm size can also be used as a signal to evaluate trustee's trustworthiness (Javenpaa et al., 2000), which we discuss further below. Structural assurance and situational normality are from institution-based trust literature, which is suggested by McKnight et al. (1998). The relationship between customization and trust relates to social psychology literature (Coelho and Henseler, 2012). Theories of competence-based and calculative-based trust-building provide the theoretical basis for considering privacy and security perceptions as antecedents of trust (Pavlou, 2001). While uncertainties in social exchange magnified by the uncertainties 
associated with the temporal and physical distances between parties on the Internet give rise to risk perceptions that increase the need to trust (Dowling, 1986; Pavlou, 2003). Each antecedent is discussed further below.

Vendor reputation refers to the consumer's belief that the vendor's website, or e-service provider, or brand has a good public image, and it is popular for consumers (Pavlou, 2003; Kim et al., 2008). Good reputation can create trust in e-commerce and increase consumers' beliefs about vendor competence, benevolence, and integrity (McKnight et al., 2002). Kim et al. (2008) found that vendor reputation positively affected trust in online shopping.

Perceived size of the vendor refers to consumers' perception of physical size of the vendor e.g., number of employees or market share (Kim and Park, 2013). Perceived size can influence trust because larger institutions are considered more capable of reliably facilitating online transactions (Kim and Park, 2013). Past studies have therefore considered perceived size as an antecedent of trust (e.g., Koufaris and Hampton-Sosa, 2004; Teo and Liu, 2007; Kim and Park, 2013).

Customization refers to the e-service provider's ability to implement a strategy to supply personalized services or products to their consumers (Srinivasn et al., 2002; Komiak and Benbasat, 2006). Some researchers (Koufaris and Hampton-Sosa, 2004; Komiak and Benbasat, 2006) considered that such customization offerings can promote trust. This is because the perception of a provider's willingness to customize a service offering provides a basis for a belief in the provider's competence and integrity.

E-service providers often collect customer's personal and/or financial information during transactions (Hagel and Rayport, 1997). For trust to materialize, a consumer should have a strong perception that security controls have been implemented by the vendor to ensure a safe online transaction environment (Kim et al., 2008).

Moreover, loss of privacy is one of the major concerns in online transacting (Malhotra et al., 2004). If an e-vendor can protect consumer's privacy, this can also improve consumer trust.

Perceived structural assurances refer to a consumer's assessment that transaction success is likely due to the existence of safety nets such as legal recourse, guarantees, and regulations that exist to protect the consumer (Gefen et al., 2003a). According to this view, if a website or eservice transaction platform is considered to be underpinned by such assurances then trust is more likely.

Situational normality refers to consumers' perception of the e-service transaction process as being normal (i.e. akin to a real world encounter) (Gefen et al., 2003a). If consumer perceives the transaction as being normal, they will feel more comfortable engaging in the transaction and hence demonstrate increased trust beliefs (Walczuch and Lundgren, 2004).

Service quality refers to quality of the service or support that the consumer received from the service provider, such as the service's responsiveness, accuracy (Petter et al., 2013). Moreover, when consumers interact with an e-service provider, high service quality can also increase consumer trust (Zhou, 2011).

Trust and perceived risk are also intuitively related to one another. One view is that risk perceptions are antecedent to trust because if the uncertainties and risk of loss are perceived to be low then there is less need to form trust perceptions (Dinev and Hart, 2006). Similarly, higher levels of risk perception will increase a consumer's need to trust (Corbitt et al., 2003).

\section{Technological-Based Antecedents}

Based on past trust research (Gefen et al., 2003a; Pavlou, 2003; Zhou, 2011), this study identified four technological-based 
antecedents. These are: perceived usefulness, perceived ease of use, information quality, and system quality.

Perceived usefulness (PU) refers to the degree to which a consumer believes that using the e-service would enhance his/her performance or effectiveness. Perceived ease of use (PEOU) refers to consumers' perceptions on whether the e-service is easy/difficult or flexible to use and interact with. These antecedents trace back to the Technology Acceptance Model of Davis (1989). When online consumers think eservice interaction media is easy to use and useful, they are more likely to trust the eservice provider (Koufaris and HamptonSosa, 2004). Moreover, Chen and Barnes (2007) argue that useful and easily understood information on web sites can lift the degree of online trust. Prior empirical studies support a link between PU, PEOU and trust (Gefen et al., 2003a; Pavlou, 2003; Wang and Benbasat, 2005). Therefore, we expect that PU and PEOU would impact on trust beliefs.

Information quality and system quality are major components of the IS Success model (DeLone and McLean, 2003). Information quality refers to the desirable characteristics of the systems outputs such as information accuracy, currency, timeliness and sufficiency (Petter et al., 2013). Systems quality refers to the desirable technical and operational characteristics of an information system such as systems' functionality, response time, navigation ease, among others (Petter et al., 2013). Therefore, we considered information quality and systems quality as technological-based antecedents. Beldad et al. (2010) argue that accurate, current and complete information can increase consumers' trust beliefs when they are transacting online. McKnight et al. (2002) argue that in initial trust building stage, high quality web site (i.e., system quality) can lead consumers' towards high trusting beliefs.

\section{Consumer Characteristics-Based antecedents}

Individual characteristics as antecedents of technology usage behaviors have been widely studied in the field of information systems (e.g., Lewis et al., 2003). Amongst these, a consumer's disposition to trust (DTT) is considered to play an important role when a consumer is interacting with an unfamiliar party (e.g. the e-service vendor) and it also can provide a necessary background for the formation of trustbuilding (Gefen, 2000). DTT is identified in the Initial Trust Formation Model (McKnight et al., 1998). Disposition to trust will be important to how consumers build interpersonal relationships (McKnight et al., 2004).

\section{Knowledge-Based Antecedents}

One of the reasons trust becomes an issue in e-service is because consumers may have little prior experience with the e-vendor (McKnight et al., 2002). Based on previous research, knowledge-based antecedents have been mainly identified as personal familiarity with the provider (e.g., Gefen et al., 2003a; He, 2011). Whilst reputation is a market-based signal, such as a good public image and popularity amongst consumers, familiarity is based on an individual consumer's past personal interactions with the vendor. Familiarity created through an interactive process where consumers and providers can get to know each other so as to better predict each other's behaviors (Lu et al., 2011). Familiarity can reduce uncertainty and simplify interpersonal relationships (Gefen, 2000). As a knowledge-based antecedent, familiarity is suggested by the theory of Trust and Power (Gefen, 2000). According to this theory, familiarity helps consumers to better understand the environment and the trusted party. Consumers learn to use particular interfaces and transact through the website or similar platforms, and they use these interactions to accumulate knowledge of the provider. This increased familiarity with both the e-service platform and the e-service 
provider can increase trust beliefs (Gefen et al., 2003a).

\section{Moderators of the Links between Trust and Its Antecedents}

Variation in the size of the effects between the above discussed antecedents and trust is observed in past studies. Understanding the causes of such variation (or lack of homogeneity in effect sizes) is important to any meta-analysis. Past meta-analyses of technology acceptance model and IS continuance model (Schepers and Wetzels, 2007; Islam and Mäntymäki, 2011) have considered the culture (Western versus Eastern) and population under study (student sample versus non-student sample) as potentially important moderators. For example, in Eastern cultures people may rely more on familiarity when building trust whilst in Western cultures people may rely more on privacy protection and risk perceptions when building trust.

E-services are both commercial (e.g., online shopping) and non-commercial (e.g., egovernment) in nature. Mou and Cohen's (2013) study considered that the type of eservice might be an important moderator between consumer trust and acceptance. Trust was found more strongly associated with acceptance of commercial e-services. Trust antecedents such as perceived risk, security, and reputation may have greater salience in contexts where financial loss may occur. Perceived usefulness, system quality and information quality may have greater importance to trust in other eservice contexts such as where performance and time loss may occur. Moreover, in contexts with a single provider (e.g. e-government) then trust may have less to do with factors such as reputation and more to do with factors such as privacy.

Numerous e-service studies have been carried out using student samples. A question that often arises in the use of such convenience samples is whether results are biased upward or downward and whether conclusions are generalizable back to a broader consumer population. Although some studies argue that when general theories are under examination, the use of student samples is valid and appropriate (Compeau et al., 2012), its remains an empirical question as to whether differences in average observed effects sizes exists across student and non-student consumer samples.

\section{Research Methodology}

Meta-analysis is defined as "the statistical analysis of a large collection of analysis results for the purpose of integrating the findings" (Glass, 1976). Through synthesizing prior empirical findings, it allows us to understand which antecedents of trust are most important in e-service and thereby address the first research question. Meta-analytic techniques can identify heterogeneity in effect sizes across studies. This allows for subsequent examination of the influence of moderators that may account for observed inconsistencies in the effect sizes reported by prior studies. Accounting for any observed heterogeneity through examination of moderators addresses our second research question. Meta-analysis has been considered as an important technique to synthesize empirical findings in Information Systems discipline (e.g., Joseph et al., 2007; Schepers and Wetzels, 2007; Liang et al., 2008; He and King, 2008; Liu et al., 2011). In the following sections we discuss our data sources and our criteria for inclusion of studies in the meta-analysis. We then discuss our procedures for data coding and analysis before presenting our results.

\section{Identifying the Studies}

To ensure the validity of the meta-analysis, we sought to include as many studies as possible. Based on our definition of eservice, we considered $\mathrm{B} 2 \mathrm{C}, \mathrm{C} 2 \mathrm{C}$ electronic commerce, electronic banking, online health services, e-government, online financial advisory service, and mobile payment services, amongst others as the context of this study. In order to select the related studies for this meta-analysis, we followed 
four phases to ensure a systematic review of prior published studies (Liberati et al., 2009). Firstly, we decided which data sources to use in this systematic review. We conducted a computerized search of the following electronic databases: EBSCO Business Source Premier, Science Direct, Jstor, Emerald and ABI/INFORM Global. To avoid the concerns of publication bias with meta-analysis (King and $\mathrm{He}, 2005$ ), we also considered conference publications via a manual search of IEEE Xplore and the AIS e-library. Our search was also supplemented with a manual search of Google Scholar and of popular e-commerce journals, namely International Journal of Electronic Commerce, Journal of Electronic Commerce Research, Electronic Commerce Research and Applications, and Electronic Commerce Research.

Secondly, we specified the search terms for study selection. Our search terms included "consumer" or "customer" or "user" or "citizen" or "individual"; "use" or "adoption" or "acceptance" or "behavioral intention"; and "trust"; and variations of "e-service" or "e-commerce" or "e-banking" or "egovernment" or "e-health" or "mobile payment" or "online". The inclusion of search terms such as "use" and "adoption" was because of the importance of trust to consumer adoption and use of e-services, and we wanted to ensure identification of papers with a focus on trust in the context of e-service use and adoption.

Thirdly, to judge which articles to include we specified the inclusion and exclusion criteria. We further restricted the time frame to articles published (or in press) between January, 2000 to December, 2013. Prior to 2000 research on consumer behaviors was mostly focused on off-line transactions. All the studies had to be accessible to the authors through their university's library system and its comprehensive electronic database subscription. In order to select the studies for this meta-analysis, we followed the following inclusion and exclusion criteria. First, the articles must focus on e-service in an online environment (e.g., e-banking service, e-government service, etc). Second, the articles must be an empirical study. Third, the articles must report correlations and sample size. Finally, the studies must include variables reflecting "trust" or "trust belief" and one or more of the antecedents of trust discussed above. Based on our inclusion and exclusion, we therefore excluded articles not reporting on results of an empirical study or papers that did not report correlations (e.g., Kim et al., 2009b; Glover and Benbasat, 2011). Furthermore, we also excluded papers where we were not able to resolve queries regarding the reported correlation matrix. In total, 67 published studies (see Appendix A) that were extracted via the research process met our inclusion/exclusion criteria and were therefore identified for inclusion in the meta-analysis.

The coding of the constructs for this metaanalysis is explained next.

\section{Coding the studies}

Each article was examined to extract data required for the meta-analysis. We independently coded the studies and discussions were held to resolve any disagreement.

We collected information on each study's sample size, inter-construct correlations and construct reliability coefficients. We identified that 35 studies were published in the last decade. 32 studies were published in the current decade. We classified articles based on the type of e-service under examination (e.g., commercial versus noncommercial). Based on the different culture dimensions (e.g., collectivism versus individualism) as identified in Hofstede and Hofstede (2005), we classified studies into Western or Eastern culture groups. Western culture groups were considered those high on individualism, whilst Eastern culture were high in collectivism. High power-distance countries were Eastern and low powerdistance is classified as Western. In classifying the culture dimensions, reference was made to Shao et al. (2013). Furthermore, we identified whether studies 
employed convenience sampling through the use of student samples. Journal, authors and published date of the articles were also recoded. The studies are summarized in Table 1.

\begin{tabular}{|c|c|c|}
\hline Years & \multicolumn{2}{|c|}{$\begin{array}{l}\text { Last decade: } 2000 \text { (1); } 2001 \text { (1); } 2002 \text { (2); } 2003 \text { (4); } 2004 \text { (3); } 2005 \text { (3); } 2006 \text { (4); } 2007 \text { (6); } \\
2008 \text { (3); } 2009 \text { (8). } \\
\text { Current decade: } 2010 \text { (9); } 2011 \text { (10); } 2012 \text { (4); } 2013 \text { (9). }\end{array}$} \\
\hline \multirow{17}{*}{ Publication types } & Publication & No of articles \\
\hline & Decision Support Systems & 5 \\
\hline & MIS Quarterly & 3 \\
\hline & International Journal of Electronic Commerce & 3 \\
\hline & Journal of Electronic Commerce Research & 3 \\
\hline & Electronic Commerce Research & 2 \\
\hline & Online Information Review & 2 \\
\hline & $\begin{array}{l}\text { Information Systems Research } \\
\text { Managing Service Quality }\end{array}$ & $\begin{array}{l}2 \\
2\end{array}$ \\
\hline & $\begin{array}{l}\text { IVlanaging service Quallty } \\
\text { Asia Pacific Journal of Marketing and Logistics }\end{array}$ & 2 \\
\hline & e-Service Journal & 2 \\
\hline & European Journal of Information Systems & 2 \\
\hline & Journal of Management Information Systems & 2 \\
\hline & Journal of the Association for Information Systems & 2 \\
\hline & OMEGA & 2 \\
\hline & Other journals & 24 \\
\hline & Conference Proceedings & 8 \\
\hline & Unpublished Manuscript & 1 \\
\hline E-service intervention & \multicolumn{2}{|c|}{$\begin{array}{l}\text { Commercial based e-services: e-commerce (37); e-banking (7); social commerce (2); mobile } \\
\text { commerce (3) e-customer service (1); e-return service (1); web-based recommendation } \\
\text { agents (1). } \\
\text { Non-commercial based e-services: e-government (1); Internet (1); peer-to-peer sharing (1); } \\
\text { location-based services (4); e-health (4); social networking (2); wi-fi hotspots (1); new } \\
\text { technology (1). }\end{array}$} \\
\hline Culture* & \multicolumn{2}{|c|}{$\begin{array}{l}\text { Western: USA (32); UK (4); Australia (1); Canada (2); New Zealand (2); The Spain (2); } \\
\text { Greece (1); Italy (1); Germany (1); Ireland (1); European (1); Brazil (1) } \\
\text { Eastern: China (10); Taiwan (7); Singapore (3); India (1); Malaysia (3); Korea (7); Qatar (1); } \\
\text { Saudi Arabia (1). } \\
\text { Mixed: Malaysia and Qatar (1). } \\
\text { Non-specified (1). }\end{array}$} \\
\hline
\end{tabular}

Notes: * > 67 due to some studies examining more than one consumer population, which were analyzed as independent samples.

We considered conceptual and operational definitions to confirm consistency between the constructs employed in the study and our definitions of trust in e-service provider and the definitions of the antecedents of trust. Variables were coded as trust if they reflected a consumer's willingness to depend on the e-service provider based on a belief or confidence in the competence, ability, integrity, benevolence, credibility and/or reliability of the e-service provider. McAllister (1995) posited a distinction between cognitive-based trust and affective- based trust. While the former is focused on trust as a belief; the later involves emotional feelings or mood. Subsequent empirical studies into e-services have shown cognitive-based trust to be the more important of the two for predicting consumer behaviors (e.g., Jarvenpaa et al., 2000; Gefen, 2002; McKnight et al., 2002). We therefore focused on cognitive trust i.e., trust as belief. We did not consider emotional or affect-based trust in this metaanalysis (e.g., Komiak and Benbasat, 2006). We also were careful to distinguish trust in 
provider in our focus versus trust in website (e.g., Lee 2005). The antecedents of trust followed the coding rules below.

\section{Reputation (REP)}

Variables were coded as REP if they reflected the consumer's belief that the vendor's website, or e-service provider, or brand has a good public image, and it is popular or has been known for a long time (Pavlou, 2003; Kim et al., 2008).

\section{Security protection (SEC)}

Variables were coded as SEC if they reflected a consumer or user's subjective assessment of the degree of vendor's security protection when they use e-service where such protection is implemented by the vendor and via the e-service platform (Kim et al. 2008), e.g. Internet environment security, perceived security, security protection and security concerns.

\section{Privacy protection (PRC)}

Variables were coded as PRC if they reflected a consumer or user's perceptions of personal information protection (Kim et al. 2008), e.g. protections against unauthorized access to, or secondary use of consumer data.

\section{Structural assurance (STA)}

Variables were coded as STA if they reflected whether the e-service vendor providers assurances for a safe transaction environment including statements of guarantees and the use of reputable transaction systems (Gefen et al., 2003a). Similar terms are technology assurance and organizational structure assurance.

\section{Situational normality (NOR)}

Variables were coded as NOR if they refer to an assessment that the e-service based interaction is typical of service in an offline context (Gefen et al. 2003a).

\section{Size (SIZ)}

Variables were coded as SIZ if they reflected the consumers' perception of physical size of the vendor or their market share (Kim and Park, 2013).

\section{Customization (CUS)}

Variables were coded as CUS if they reflect the e-service provider's ability to implement a strategy to supply personalized services to their consumers, e.g., perceived personalization (Komiak and Benbasat, 2006).

\section{Service quality (SEQ)}

Variables were coded as SEQ if they reflected whether the e-service provider is considered responsive and professional in dealing with consumers (Petter et al., 2013).

\section{Perceived risk (PR)}

Variables were coded as risk if they reflected a consumer's overall subjective assessment of the potential for loss associated with using the e-service (Pavlou, 2003).

\section{Perceived ease of use (PEOU)}

Variables were coded as PEOU if they reflected consumer perceptions on whether the e-service is easy/difficult or flexible to use and interact with (Pavlou, 2003).

\section{Perceived usefulness (PU)}

Variables were coded as PU if they reflected the degree to which a consumer believes that using the e-service would enhance his/her performance or effectiveness (Pavlou, 2003). These performance benefits could include convenience, cost savings, effectiveness, and time savings.

\section{Information quality (INQ)}

Variables were coded as INQ if they reflected whether the e-service vendor can provide sufficient, accurate, timely and comprehensive information outputs (Kim et al., 2008; Petter et al., 2013).

\section{System quality (SYQ)}

Variables were coded as SYQ if they reflected whether e-service website or platform has a good layout, speed of 
navigation and availability (up and running) (Petter et al., 2013).

\section{Familiarity (FAM)}

Variables were coded as FAM if they reflected a knowledge-based familiarity i.e., the extent to which the consumer is familiar with or has experience with the e-service, or e-vendor (Gefen et al., 2003a).

\section{Disposition to trust (DTT)}

Variables were coded as DTT if they reflected a consumer's general tendency (personality-based) to believe in or trust other people (Kim et al., 2008), e.g. trust propensity, trust stance, dispositional trust or propensity to trust.

\section{Recording Effect Sizes}

The authors independently coded each study's reported effect sizes (i.e., the correlations). These were then crosschecked for agreement. In certain cases, where only inter-item correlations were reported (e.g., Gefen, 2000; Bhattacherjee, 2002), we calculated the inter-construct correlations as the average of the respective inter-item correlations. We reversed the direction of correlations in those cases where measurement items were phrased in the negative e.g. to reflect privacy concerns and security concerns as opposed to perceived privacy protection and perceived security protection.

In addition to the effect sizes, we coded the reliabilities of each study's variables using the reported Cronbach's alpha coefficient or if not available the reported composite reliability or internal consistency scores. Based on the reported reliabilities across all the studies, we calculated an average reliability score for each variable for use in subsequent analysis.

\section{Meta-Analytic Approach}

This study followed the methods of Hunter and Schmidt's (2004) random effects models to estimate effect sizes. First, to correct for sampling error, we calculated weighted mean effect size $\left(r_{+}\right)$. This approach weights each study's correlation by the number of observations in that study according to the formula:

$$
r_{+}=\frac{\sum_{i=1}^{k} N_{i} r_{i}}{\sum_{i=1}^{k} N_{i}}
$$

Where $N_{i}$ is the sample size of each study and $r_{i}$ is the observed correlation value of each study.

Second, to correct for measurement error, we calculated the true-score correlation $\left(r_{c}\right)$ by using the following formula:

$$
\boldsymbol{r}_{c}=\frac{\boldsymbol{r}_{x y}}{\sqrt{\boldsymbol{r}_{x x} \boldsymbol{r}_{y y}}}
$$

Where $r_{x y}$ is the average observed correlation across the studies, $r_{x x}$ is the average of the reported reliability estimates for the independent variable, and $r_{y y}$ is the average of the reported reliability estimates for the dependent variable.

Third, following Hedges and Olkin's (1985) recommendation, we also carried out homogeneity tests to determine whether there is any heterogeneity in the underlying correlations. To do homogeneity test, we first did the Fisher $Z$ transformation, which is used to compute each r's corresponding $Z \mathrm{Zr}_{\mathrm{i}}$ by using the formula:

$$
Z_{r_{i}}=\frac{1}{2} \log _{e}\left(\frac{1+r_{i}}{1-r_{i}}\right)
$$

Where $r_{i}$ is the observed correlation value of each study.

Then we calculated Homogeneity $Q$, which is used to estimate the possible moderator effects by using the formula:

$$
Q=\sum_{i=1}^{k}\left(\mathcal{W}_{i}\right)\left(\bar{z}_{r}\right)^{2}
$$

Where

$$
\bar{z}_{r}=\frac{\sum_{i=1}^{k} \mathcal{w}_{i} z_{r_{i}}}{\sum_{i=1}^{k} w_{i}}=\frac{\sum_{i=1}^{k}\left(N_{i}-3\right) z_{r_{i}}}{\sum_{i=1}^{k}\left(N_{i}-3\right)}
$$


Where $N_{i}$ is the sample size of each study and $\mathrm{W}_{\mathrm{i}}$ is $\mathrm{N}_{\mathrm{i}}-3$.

If $Q$ exceeds the critical value, moderating effects should be suspected (Schepers and Wetzels, 2007).

Finally, the fail-safe test is used to test the robustness of the findings and to provide for an indication of publication bias by estimating the number of non-significant results or non-published studies that would be required to reduce an obtained mean effect size to a trivial level (Rosenthal, 1979). A general rule of thumb is that the fail safe $\mathrm{N}$ value should exceed $5 k+10$ (where $k$ is the number of observed correlations).

\section{Results}

RQ1: What are the key antecedents of trust in the e-service context?
The descriptive statistics and meta-analysis results are presented in Tables 2 through 4. For each antecedent, we report the total number of studies, the total number of observed correlations, and range of correlation, average correlation, and range of sample size, the total sample size and the average of sample size. Because some publications reported results from tests on more than one sample under examination, the number of available pair-wise correlations could exceed the number of publications. Then, we calculated $r_{+}, r_{c}$, the variance of $r_{+}$and $r_{c}$, standard deviation of $r_{c}$, and $95 \%$ confidence and credibility interval of $r_{+}$. We also did a fail-safe $\mathrm{N}$ test to further evaluate the significance of each antecedent of trust. To do the fail-safe $\mathrm{N}$ test, we first transformed $r$ to Cohen's $d$ value, and then we adopted Orwin's formula to calculate the fail-safe $\mathrm{N}$.

\section{Table 2 - Vendor and Institution-Based Antecedents of Trust}

\begin{tabular}{|c|c|c|c|c|c|c|c|c|c|c|}
\hline & \multicolumn{9}{|c|}{ Vendor and Institution-Based Antecedents of Trust } \\
\hline & & REP & SEC & PRC & STA & NOR & SIZ & CUS & SEQ & PR \\
\hline \multicolumn{2}{|l|}{ Number of studies } & 11 & 12 & 23 & 15 & 8 & 3 & 5 & 6 & 24 \\
\hline \multicolumn{2}{|l|}{ Number of correlations } & 15 & 14 & 25 & 20 & 10 & 5 & 6 & 6 & 28 \\
\hline \multicolumn{2}{|l|}{ Total sample size } & 6270 & 4133 & 9176 & 6654 & 3884 & 3589 & 1265 & 1498 & 10663 \\
\hline \multicolumn{2}{|l|}{ Average sample size } & 418 & 295 & 367 & 333 & 388 & 718 & 211 & 250 & 381 \\
\hline \multirow{2}{*}{ Range of sample size } & Lower & 52 & 52 & 52 & 76 & 76 & 305 & 100 & 160 & 52 \\
\hline & Upper & 1381 & 452 & 1153 & 910 & 910 & 1381 & 357 & 360 & 1381 \\
\hline \multirow{3}{*}{ Correlations } & Lower & 0.250 & 0.110 & 0.010 & 0.200 & 0.180 & 0.100 & 0.158 & 0.189 & -0.080 \\
\hline & Upper & 0.691 & 0.689 & 0.700 & 0.872 & 0.815 & 0.370 & 0.520 & 0.760 & -0.810 \\
\hline & Average & 0.524 & 0.445 & 0.310 & 0.539 & 0.442 & 0.279 & 0.375 & 0.489 & -0.379 \\
\hline \multicolumn{2}{|r|}{ Fing } & 0.588 & 0.407 & 0.270 & 0.581 & 0.472 & 0.305 & 0.361 & 0.506 & -0.400 \\
\hline \multicolumn{2}{|l|}{$r_{c}$} & 0.603 & 0.506 & 0.353 & 0.625 & 0.521 & 0.333 & 0.435 & 0.556 & -0.433 \\
\hline \multicolumn{2}{|l|}{ Var $r_{+}$} & 0.018 & 0.037 & 0.053 & 0.039 & 0.033 & 0.009 & 0.022 & 0.050 & 0.041 \\
\hline \multicolumn{2}{|l|}{ Var $r_{c}$} & 0.022 & 0.044 & 0.066 & 0.050 & 0.043 & 0.011 & 0.024 & 0.060 & 0.050 \\
\hline \multicolumn{2}{|l|}{$\mathrm{SD}\left(\mathrm{r}_{\mathrm{c}}\right)$} & 0.149 & 0.210 & 0.257 & 0.223 & 0.207 & 0.105 & 0.156 & 0.246 & 0.224 \\
\hline \multirow{2}{*}{$\begin{array}{l}95 \% \text { Confidence } \\
\text { interval }\left(r_{+}\right)\end{array}$} & Lower & 0.520 & 0.307 & 0.180 & 0.480 & 0.331 & 0.239 & 0.241 & 0.329 & -0.473 \\
\hline & Upper & 0.656 & 0.507 & 0.360 & 0.681 & 0.614 & 0.371 & 0.482 & 0.683 & -0.327 \\
\hline \multirow{2}{*}{$\begin{array}{l}\text { 95\% Credibility interval } \\
\left(\mathrm{r}_{+}\right)\end{array}$} & Lower & 0.331 & 0.045 & 0.171 & 0.138 & 0.032 & 0.174 & 0.090 & 0.083 & -0.777 \\
\hline & Upper & 0.854 & 0.769 & 0.711 & 1.023 & 0.912 & 0.436 & 0.632 & 0.930 & -0.023 \\
\hline \multicolumn{2}{|l|}{$5 k+10$} & 85 & 80 & 135 & 110 & 60 & 35 & 40 & 40 & 150 \\
\hline \multicolumn{2}{|l|}{ Fail-safe N (0.05) } & 354 & 264 & 301 & 492 & 187 & 53 & 87 & 129 & 431 \\
\hline \multicolumn{2}{|l|}{ Result } & sig & sig & sig & sig & sig & sig & sig & sig & sig \\
\hline
\end{tabular}

Notes: $r_{+}$: Weighted mean effect size; $r_{c}$ : Trust-score effect size; Var $r_{+}:$Variance of the weighted mean effect size; Var $r_{c}$ : Variance of the true-score effect size; Sig: Significant; Var: Variance; SD $\left(r_{c}\right)$ : Standard deviation of $r_{c}$. 
The meta-analysis results for the vendor and institution-based antecedents (Table 2) indicate that none of the $95 \%$ confidence intervals contain zero, hence, all the antecedents have a significant correlation with trust. This indicates that all of the vendor and institution-based antecedents are important to consumer trust in eservices context. Among them, REP $\left(r_{+}\right.$ $=0.588$ ) has the strongest effects size on trust. STA, NOR and SEQ also showed high correlations with trust in provider in $\mathrm{e}$ service context. However, PRC $\left(r_{+}=0.270\right)$ has the weakest effects size on trust. Variables such as SIZ $\left(r_{+}=0.305\right)$, CUS $\left(r_{+}\right.$ $=0.361)$ and SEC $\left(r_{+}=0.407\right)$ have medium effects on trust. We calculated 95\% credibility intervals (Hunter and Schmidt,
2004). If the intervals are sufficiently large or include zero, then the presence of moderators should be expected (Petter and McLean, 2008). All of nine antecedents have a large credibility interval. So, this requires further moderator analysis, which we present below. All the antecedents passed the fail-safe $\mathrm{N}$ test as the fail safe $\mathrm{N}$ values exceed $5 k+10$ (where $k$ is the number of observed correlations), which indicate the number of additional studies with non-significant findings that would be required before the average effect size could be considered non-significant. The values reported here provide additional confidence in the overall significance of these effect sizes.

\section{Table 3 - Technological, Knowledge and Consumer-Based Antecedents of Trust}

\begin{tabular}{|c|c|c|c|c|c|c|c|}
\hline \multicolumn{2}{|l|}{ Knowledge-Based } & \multicolumn{4}{|c|}{ Technological-Based } & \multirow{2}{*}{$\begin{array}{c}\begin{array}{c}\text { Consumer- } \\
\text { Based }\end{array} \\
\text { DTT }\end{array}$} & \multirow{2}{*}{$\begin{array}{c}\text { Knowledge } \\
\text { Based }\end{array}$} \\
\hline & & PU & PEOU & INQ & $S Y Q$ & & \\
\hline \multicolumn{2}{|l|}{\begin{tabular}{|l|} 
Number of studies \\
\end{tabular}} & 19 & 26 & 11 & 8 & 13 & 16 \\
\hline \multicolumn{2}{|l|}{\begin{tabular}{|l|} 
Number of correlations \\
\end{tabular}} & 24 & 31 & 14 & 10 & 20 & 21 \\
\hline \multicolumn{2}{|l|}{ Total sample size } & 7540 & 10318 & 5581 & 3729 & 9364 & 9043 \\
\hline \multicolumn{2}{|l|}{ Average sample size } & 314 & 333 & 399 & 373 & 468 & 431 \\
\hline \multirow{2}{*}{ Range of sample size } & Lower & 52 & 52 & 215 & 158 & 122 & 76 \\
\hline & Upper & 910 & 1153 & 1153 & 910 & 1381 & 3260 \\
\hline \multirow{3}{*}{ Correlations } & Lower & 0.090 & 0.064 & 0.100 & 0.180 & 0.140 & 0.100 \\
\hline & Upper & 0.738 & 0.704 & 0.820 & 0.682 & 0.567 & 0.690 \\
\hline & Average & 0.503 & 0.445 & 0.416 & 0.500 & 0.370 & 0.349 \\
\hline \multicolumn{2}{|l|}{$r_{+}$} & 0.532 & 0.467 & 0.404 & 0.502 & 0.374 & 0.386 \\
\hline \multicolumn{2}{|l|}{$r_{c}$} & 0.572 & 0.509 & 0.486 & 0.569 & 0.424 & 0.406 \\
\hline \multicolumn{2}{|l|}{ Var $r_{+}$} & 0.030 & 0.033 & 0.033 & 0.032 & 0.013 & 0.021 \\
\hline \multicolumn{2}{|l|}{ Var $r_{c}$} & 0.035 & 0.040 & 0.041 & 0.061 & 0.015 & 0.026 \\
\hline \multicolumn{2}{|l|}{$\mathrm{SD}\left(\mathrm{r}_{\mathrm{c}}\right)$} & 0.188 & 0.200 & 0.203 & 0.197 & 0.123 & 0.160 \\
\hline \multirow{2}{*}{$\begin{array}{l}95 \% \text { Confidence } \\
\text { interval }\left(r_{+}\right)\end{array}$} & Lower & 0.437 & 0.404 & 0.322 & 0.381 & 0.323 & 0.318 \\
\hline & Upper & 0.626 & 0.531 & 0.487 & 0.623 & 0.425 & 0.454 \\
\hline \multirow{2}{*}{$\begin{array}{l}95 \% \text { Credibility interval } \\
(r+)\end{array}$} & Lower & 0.076 & 0.123 & 0.106 & 0.127 & 0.159 & 0.087 \\
\hline & Upper & 0.988 & 0.812 & 0.703 & 0.877 & 0.589 & 0.686 \\
\hline \multicolumn{2}{|l|}{$5 \mathrm{k}+10$} & 130 & 165 & 80 & 60 & 110 & 115 \\
\hline \multicolumn{2}{|l|}{ Fail-safe N (0.05) } & 535 & 585 & 242 & 221 & 318 & 278 \\
\hline \multicolumn{2}{|l|}{ Result } & sig & sig & sig & sig & sig & sig \\
\hline
\end{tabular}


The meta-analysis results of technologicalbased antecedents (PU, PEOU, INQ and SYQ) (Table 3) indicate that all of four antecedents have significant and strong effects on trust $\left(r_{+}\right.$ranged from 0.404 to 0.532). Among them, we obtained 31 correlations between PEOU and TR, 24 correlations between PU and TR. However, we only obtained 10 correlations between SYQ and TR. All the true-score correlations are larger than 0.400 . These findings suggest that trust has important interrelationships with both TAM (PU and PEOU) and IS Success models (INQ and SYQ). This suggests they can be usefully examined together with trust in the e-service context. However, comparing the lower and upper correlation reveals large difference in the correlations across studies. The large credibility intervals indicate that potential moderators may exist.

Knowledge-based antecedent (FAM) and consumer-based antecedent (DTT) (Table 3) are also confirmed as having significant correlations with trust in the e-service context. Both FAM and DTT have similar effect sizes on trust. For FAM, the truescore correlation $\left(r_{c}\right)$ is 0.406 , and for DTT, the true score-correlation is 0.424 . Our results indicated that both FAM and DTT are important to trust beliefs in the eservices context. But credibility intervals suggest they may be relatively more important in some contexts than in others. We consequently explore moderating effects next.

RQ2: To what extent are these antecedents moderated by factors such as culture, type of e-service, and sampling strategy?

The results of testing for moderation effects are reported in Table 4 . In addition to the large credibility intervals (Table 2-3), Table 4 shows that $Q$ values exceed the critical value for all antecedents, confirming the need for moderators to be examined. We considered three moderators for their potential moderating effects, namely culture of consumer population (Western versus Eastern), sampling strategy (student versus non-student sample), and type of e-service (commercial versus non-commercial). In one study (Kassim and Abdullah, 2010), two different cultures sample were pooled in one data set and, hence, we excluded it from moderator analysis. Where no studies existed in certain cases (e.g., no noncommercial e-service contexts examining correlations between vendor size and trust), we do not report moderator effects.

Table 4 shows that beside perceived risk, culture was found to moderate all the effect sizes. This finding confirms the important influence of culture in e-services research (Benbasat et al., 2008). In all cases, studies classified as having been carried out in Eastern cultures reported stronger effect sizes than those carried out in Western cultures. The moderation effects of sampling strategy (student sample versus non-student sample) was significant for REP, SEC, PRC, STA, NOR, CUS, PR, FAM, INQ and SYQ. Type of e-service (commercial versus non-commercial) moderated all the effect sizes except for SYQ, PRC and DTT with certain antecedents more important to trust in commerical and others more important in non-commercial contexts. Specifically, REP, STA, NOR, PR, PU and PEOU are important to trust in commercial contexts, while SEC, INQ, and FAM are more important to trust in non-commercial contexts. 


\begin{tabular}{|c|c|c|c|c|c|c|c|c|c|c|c|}
\hline & \multirow{2}{*}{ Q } & \multirow{2}{*}{$\begin{array}{l}\text { Critical } \\
\text { Value }\end{array}$} & \multicolumn{3}{|c|}{ Sampling Strategy } & \multicolumn{3}{|c|}{ Culture } & \multicolumn{3}{|c|}{ Type of E-service } \\
\hline & & & $\mathrm{s}$ & NS & Z & $\mathrm{W}$ & $E$ & Z & $\mathrm{C}$ & $\mathrm{NC}$ & $\bar{Z}$ \\
\hline REP & 173.5 & 23.69 & 0.592 & 0.446 & 7.343 & 0.507 & 0.571 & -3.566 & 0.562 & 0.369 & 6.299 \\
\hline SEC & 268.9 & 22.36 & 0.393 & 0.514 & -4.885 & 0.376 & 0.577 & -7.520 & 0.426 & 0.689 & -4.922 \\
\hline PRC & 678.2 & 36.42 & 0.268 & 0.363 & -4.872 & 0.282 & 0.434 & -7.360 & 0.315 & 0.310 & 0.636 \\
\hline STA & 1052.6 & 30.14 & 0.444 & 0.716 & 17.166 & 0.376 & 0.648 & -14.676 & 0.564 & 0.441 & 5.038 \\
\hline NOR & 472.1 & 16.92 & 0.428 & 0.498 & -2.661 & 0.408 & 0.464 & -2.112 & 0.460 & 0.400 & 1.98 \\
\hline SIZ & 20.1 & 9.49 & 0.309 & 0.235 & 1.87 & 0.193 & 0.337 & -3.947 & 0.279 & - & - \\
\hline CUS & 37.64 & 11.07 & 0.500 & 0.312 & 2.926 & 0.346 & 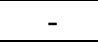 & - & 0.375 & - & - \\
\hline SEQ & 151.3 & 11.07 & 0.587 & 0.470 & 1.932 & 0.352 & 0.755 & -10.38 & 0.489 & - & - \\
\hline PR & 727.8 & 40.11 & -0.367 & -0.407 & 2.22 & -0.373 & -0.388 & 0.904 & -0.406 & -0.336 & -3.579 \\
\hline $\mathrm{PU}$ & 377.9 & 35.17 & 0.503 & 0.502 & 0.057 & 0.418 & 0.587 & -9.241 & 0.539 & 0.250 & 7.085 \\
\hline PEOU & 470.6 & 43.77 & 0.455 & 0.437 & 1.060 & 0.377 & 0.507 & -7.487 & 0.470 & 0.080 & 7.144 \\
\hline INQ & 274.0 & 22.36 & 0.387 & 0.438 & -2.260 & 0.298 & 0.491 & -8.156 & 0.377 & 0.647 & -8.483 \\
\hline SYQ & 237.1 & 16.92 & 0.400 & 0.650 & -10.690 & 0.406 & 0.594 & -7.715 & 0.492 & 0.574 & -1.399 \\
\hline FAM & 337.1 & 31.41 & 0.399 & 0.381 & -2.291 & 0.286 & 0.452 & -8.415 & 0.338 & 0.571 & -2.529 \\
\hline DTT & 167.5 & 30.14 & 0.358 & 0.387 & -1.622 & 0.327 & 0.445 & -6.605 & 0.381 & 0.326 & 1.888 \\
\hline
\end{tabular}

Notes: S: Student; NS: Non-student; Z: Z-value; W: Western; E: Eastern; C: Commercial-based e-service; NC: Non-commercial-based e-service.

\section{Discussion}

This study aimed to synthesize past empirical findings of the antecedents of trust in e-service context through a meta-analysis of 67 empirical studies. The antecedents of trust were classified as: vendor and institution-based; technological-based; knowledge-based and consumer-based. The study also attempted to identify the potential moderators that may influence the effects sizes across studies. Sampling strategy (student sample versus nonstudent sample), culture (Western versus Eastern) and type of e-service (commercial e-service versus non-commercial e-service) were considered. Data was collected via scholarly databases. Our study results in several important findings.

Firstly, the meta-analysis results of vendor and institution-based antecedents indicated that all of the antecedents are significantly related to consumer trust in the e-service context. Among the investigated factors, structural assurance $\left(r_{+}=0.581\right)$, vendor reputation $\left(r_{+}=0.588\right)$, service quality $\left(r_{+}\right.$ $=0.506)$, perceived security protection $\left(r_{+}\right.$ $=0.407)$, normality $\left(r_{+}=0.472\right)$ and perceived risk $\left(r_{+}=-0.400\right)$ have stronger effects (above 0.400) than others antecedents on trust. These findings are consistent with prior meta-analysis of trust in e-commerce (e.g., He, 2011). We found vendor size $\left(r_{+}\right.$ $=0.305)$ and privacy protection $\left(r_{+}=0.238\right)$ having the lowest effects on trust in this category.

Secondly, prior studies have shown trust is positively associated with perceived usefulness and perceived ease of use (e.g., Pavlou, 2003; Gefen et al., 2003a). Our meta-analysis of technological-based antecedents revealed that all the four factors are strongly correlated with trust (effect sizes above 0.400). Trust has strong links with all the TAM and IS Success model variables suggesting that trust can be usefully integrated into those theories in future explanations of e-service use and satisfaction.

Thirdly, past studies addressed that knowledge and consumer-based antecedents are important to form consumer trust in various e-services (e.g., Gefen et al., 2003a; Kim et al., 2008). Our meta-analysis results confirmed that familiarity and disposition to trust are important to form trust. However, the effect sizes of familiarity $\left(r_{+}=0.386\right)$ and disposition to trust $\left(r_{+}=0.374\right)$ are lower, 
suggesting they are less important for trust than technological based antecedents. Overall, both vendor and technology based antecedents have been found more important to trust than consumer or knowledge-based factors.

Fourthly, interestingly, most of the effect sizes had large credibility intervals. Furthermore, homogeneity $Q$ value is larger than critical value in our study. All these indicated that potential moderators existed and should be investigated. To address the potential moderators, we considered sampling strategy, culture and type of eservice as the moderators. Through our moderator analysis, we found culture almost moderated the effects of all the antecedents of trust. This finding confirms suggestions made elsewhere (Benbasat et al., 2008). In particular, the effect sizes were stronger in Eastern than Western contexts for all antecedents examined. This suggests that trust building may be especially difficult in Eastern contexts where reputation and familiarity are important alongside issued of security, privacy and technology factors. Beside perceived privacy protection, type of e-service moderated all of the vendor and institution-based antecedents where the salience in commercial e-service contexts was most important. Antecedents such as familiarity, information quality, and security were however mostly important for noncommercial contexts. Thus consideration of the e-service context is important to study design and the relative importance of certain variables in the e-service context under study must be considered in future research.

There were few differences across student versus non-student samples with reputation, customization and service quality more important to students, whilst structure assurances, security, situational normality, information quality and system quality were more important to non-students.

\section{Implications and Conclusion}

\section{Implications for Research}

This study has several valuable implications for researchers. First, our study extended trust in e-commerce context to trust in eservices. We found that trust is not only salient in commercial e-service contexts but also extends to the non-commercial context (e.g., e-government and e-health), which can help researchers to better understand the importance of trust in both commercial and non-commercial context. Moreover, we have confirmed that trust has a number of antecedents, and have presented both aggregate effect sizes as well as considered the potential for moderating effects. Our classification of antecedents of trust into vendor and institution-based; technologicalbased; knowledge-based and consumerbased may also provide a useful framework for future research.

Second, a base from which to report effect sizes for various antecedents of trust has been established which provide a benchmark against which future studies can compare their effect sizes. For example, a recent study by Moody et al. (2014), which fell outside our publication period under review, reported effect sizes between trust, disposition to trust, and situational normality that fall with the ranges reported in Table 2 and 3. However, while the trust-situational normality link is close to our average effect size, disposition to trust is on the lower side of previously reported effect sizes. Our study can provide a basis for researchers to explore why differences in effect size are observed across contexts. Moody et al. studied a student sample in a western context, which have on average lower reported effect sizes around the disposition to trust construct. Moreover, our results can also help researchers to better understand which antecedents are relatively more important to form consumer trust in eservice context that should be tested in their studies. For instance, factors such as structural assurance, reputation, perceived usefulness, and perceived ease of use, 
system quality and service quality are particularly important to associate with trust. Moreover, trust has strong links with all the TAM and IS Success model variables, researchers may therefore wish to integrate those theories into future explanations of eservice use and satisfaction.

Third, by examining the heterogeneity of effects sizes, we were able to identify important moderating effects. The moderator analysis also revealed an important implication for researchers. In particular, the specific selection of antecedents should take the culture context into account, and classify the commercial and non-commercial nature of the e-service. Based on their classification determine which antecedents are most important for inclusion. For example, our meta-analysis results found that perceived privacy protection and vendor size have lesser effects on trust. Studies of non-commercial e-services should pay particular attention to information quality. This may be especially relevant to non-commercial services such as online information providers.

\section{Implications for Practice}

This study also has several important practical implications. Firstly, this study provided insights into the relative importance of different antecedents of trust which can be useful for guiding practitioners to focus on trust-building mechanisms. With this understanding, practitioners will be better positioned to establish their online service offerings. In particular, the importance of factors such as system, information and service quality was confirmed, as well as those such as vendor reputation, and situational normality. All of these factors are within the vendor's control and can be manipulated through interventions so as to improve consumer trust. For example, e-service providers should consider whether their online transaction platform is stable, reliable and dependable (SYQ), work on their public image (REP), make sure that their transaction platform is flexible to interact with and easy to operate (PEOU), and make sure whether their e-service can improve consumer's performance and enhance their effectiveness (PU). Moreover, e-vendors should provide on-time services and prompt response to user's questions or problems (SEQ). The nature of the interaction with the transaction platform should appear typical of other similar transaction platforms (FAM), as well as make sure users can feel safe when conducting business with the online vendor because of its statements of guarantees and ethics charter (STA).

Secondly, our results also have strong implications for search engine design. For example, traditionally search engines like Google ranked results using number of links to a site (a potential proxy for site reputation). Our results support this with our finding that reputation has the strongest effect size with consumer trust. Recently, Dong et al. (2015) reported that Google researchers were considering an alterative based on the quality of a site's facts (information content) as a determinant of its trustworthiness and therefore how it should be ranked in search results. Our finding with respect to information quality supports this thinking, especially if information quality improves the perceived usefulness of a site, which we found is another strong antecedent of trust. However, we found that structural assurance, system quality, and service quality are somewhat more important than information quality to trust. This suggests that search engine researchers may wish to consider search algorithms that focus not just on reputation or information quality but also on evaluations of site adherence to structural assurance mechanisms, the dependability of site's underlying technology platform (system quality), and any potential proxies for service quality.

Lastly, our results confirmed that all the antecedents were moderated by culture. This is particularly important to global firms. The practitioners may build different eservice promotion strategies across different cultures/countries. For instance, in Eastern 
culture, we found the antecedents of trust revealed stronger effects sizes than Western culture particularly with regards to technological-based antecedents and some vendor factors. This suggests that e-service providers should pay more attention on their trust building strategy in Eastern culture around those factors.

\section{Limitations and Future Research}

Some important limitations to the study are recognized. First, as in all meta-analyses, our findings are influenced by the quality of the underlying methods used in the primary empirical studies. Second, only studies that reported correlations and sample sizes can be include in the analysis. Third, the focus on quantitative studies results in the exclusion of qualitative studies that may provide useful insights into trust building amongst consumers. Fourth, although several research databases were reviewed for relevant studies, resource constraints limit the number of research databases that can be covered and that are accessible to the researcher. Fifth, by aggregating findings from across studies, meta-analytic work loses information about the original study contexts (Mou and Cohen, 2013). Meta-analyses have also been criticized for mixing "apples" and "oranges". This is because a meta-analytic study may mix studies with different characteristics. To avoid this problem, two authors of this study separately coded all of the 67 studies to ensure correspondence with the definitions of e-service and the conceptualization of the variables under study and any disagreements were resolved with discussions. Moreover, we attempted to account for some of the contextual differences across studies through our moderator analysis. Sixth, we considered eservices that are both commercial and noncommercial, future research may draw on other typologies to organize the e-service context. Seventh, the studies included in our meta-analysis were carried out in many disciplines e.g., information systems and marketing. This results in a rich sample set, which on the one hand provides the opportunity to contribute a synthesized analysis, but on the other hand lose the context information which may weaken the credibility of findings.

Our moderator analysis provides only a partially contextualized view of the relationships under study. Due to the lack of sufficient studies exploring correlations between trust and other variables, we could not include all possible antecedents, such as third party seals, past experience, and self-efficacy. A meta-analysis of the relationships between consumer trust and these variables deserve further consideration in our future research once a sufficient number of correlations have been observed.

\section{Conclusion}

This study carried out a meta-analysis of the antecedents of consumer trust in e-services context. We synthesized the antecedents of trust in e-service using 67 previously published studies. The findings showed that structural assurance, reputation, perceived usefulness, system quality and services quality demonstrate the strongest effect sizes on trust. We considered explanations for identified heterogeneity in effect sizes through moderator analysis. We found that cultural context of the study almost moderated all the effect sizes with relationships strongest in Eastern contexts. Certain effect sizes were also moderated by factors such as the type of e-service and the use of student samples.

\section{Acknowledgements}

We would like to thank the editor and two anonymous reviewers for their comments, which have greatly improved this paper. An earlier version of this work was presented at the 18th Pacific Asia Conference on Information Systems (PACIS 2014), Chengdu, China. 


\section{Reference}

* References marked with an asterisk refer to studies included in the Meta-analysis

*Aldás-Manzano, J., Lassala-Navarré, C., Ruiz-Mafé, C. and Sanz-Blas, S. (2009). "Key Drivers of Internet Banking Services Use," Online Information Review, 33(4), pp.672695.

*Azam, A., Qiang, F., Abbas, S.A. and Abdullah, M.I. (2013). "Structural Equation Modeling (SEM) Based Trust Analysis of Muslim Consumers in the Collective Religion Affiliation Model in E-Commerce," Journal of Islamic Marketing, 4(2), pp.134-149.

*Bansal, G., Zahedi, F.M. and Gefen, D. (2010). "The Impact of Personal Dispositions on Information Sensitivity, Privacy Concern and Trust in Disclosing Health Information Online," Decision Support Systems, 49, pp.138-150.

Beatty, P., Reay, I., Dick, S. and Miller, J. (2011). "Consumer Trust in ECommerce Web Sites: A MetaStudy," ACM Computing Surveys, 43(3), article 14.

Beldad, A., de Jong, M. and Steehouder, M. (2010). "How Shall I Trust the Faceless and the Intangible? A Literature Review on the Antecedents of Online Trust," Computer in Human Behavior, 26, pp.857-869.

Bélanger, F. and Carter, L. (2008). "Trust and Risk in E-Government Adoption," Journal of Strategic Information Systems, 17, pp.165-176.

Benbasat, I., Gefen, D. and Pavlou, P. (2008). "Special Issue: Trust in Online Environments," Journal of Management Information Systems, 24(4), pp.5-11.

*Bhattacherjee, A. (2002). "Individual Trust in Online Firms: Scale Development and Initial Test," Journal of
Management Information Systems, 19(1), pp.211-241.

Boyer, K.K., Hallowell, R. and Roth, A. V. (2002). "E-Services: Operations Strategy - A Case Study and a Method for Analyzing Operational Benefits," Journal of Operations Management, 20(2), pp.175-188.

*Casaló, L.V., Flvián, C. and Guinalíu, M. (2011). "The Generation of Trust in the Online Services and Product Distribution: The Case of Spanish Electronic Commerce," Journal of Electronic Commerce Research, 12(3), pp.199-213.

Chandra, S., Srivastava, S.C. and Theng Y.L. (2010). "Evaluating the Role of Trust in Consumer Adoption of Mobile Payment Systems: An Empirical Analysis," Communications of the Association for Information Systems, 27, pp.561588.

${ }^{*}$ Chang, Y.S. and Fang, S.R. (2013). "Antecedents and Distinctions Between Online Trust and Distrust: Predicting High-and Low-Risk Internet Behaviors," Journal of Electronic Commerce Research, 14(2), pp.149-166.

*Chellappa, R.K. (2008). "Consumers' Trust in Electronic Commerce Transactions: The Role of Perceived Privacy and Perceived Security," Unpublished Manuscript, 1-38.

Chen, Y.H. and Barnes, S. (2007). "Initial Trust and Online Buyer Behaviour," Industrial Management \& Data Systems, 107(1), pp.21-36.

*Chen, J. and Dibb, S. (2010). "Consumer Trust in the Online Retail Context: Exploring the Antecedents and Consequences," Psychology \& Marketing, 27(4), pp.323-346.

${ }^{*}$ Chen, M.Y. and Teng, C.I. (2013). "A Comprehensive Model of the Effects of Online Store Image on Purchase Intention in an E-Commerce 
Environment," Electronic Commerce Research, 13, pp.1-23.

${ }^{*}$ Chiu, C.M., Chang, C.C., Cheng, H.L. and Fang, Y.H. (2009). "Determinants of Customer Repurchase Intention in Online Shopping," Online Information Review, 33(4), pp.761784.

Cho, V. (2006). "A Study of the Roles of Trusts and Risks in InformationOriented Online Legal Services Using an Integrated Model," Information and Management, 43, pp.502-520.

${ }^{*}$ Cho, D.Y., Kwon, H.J. and Lee, H.Y. (2007). "Analysis of Trust in Internet and Mobile Commerce Adoption," Proceedings of the 40th Hawaii International Conference on System Sciences.

${ }^{*}$ Chung, K.H. and Shin, J.I. (2010). "The Antecedents and Consequents of Relationship Quality in Internet Shopping," Asia Pacific Journal of Marketing and Logistics, 22(4). pp.473-491.

Coelho, P.S. and Henseler, J. (2012). "Creating Customer Loyalty Through Service Customization," European Journal of Marketing, 46(3/4), pp.331-356.

Compeau, D., Marcolin, B., Kelley, H. and Higgins, C. (2012). "Research Commentary Generalizability of Information Systems Research Using Student Subjects-A Reflection on Our Practices and Recommendations for Future Research," Information Systems Research, 23(4), pp.1093-1109.

Corbitt, B.J., Thanasankit, T. and $\mathrm{Yi}, \mathrm{H}$. (2003). "Trust and E-commerce: A Study of Consumer Perceptions," Electronic Commerce Research and Applications, 2, pp.203-215.

${ }^{*}$ Curry, P. (2011). "Consumer Risk: The Importance of Privacy and Security While Connected to Wi-Fi Hotspots: Does Location Matter?" Proceedings of the Seventeenth Americas
Conference on Information Systems, paper 308.

Davis, F.D. (1989). "Perceived Usefulness, Perceived Ease of Use, and User Acceptance of Information Technology," MIS Quarterly, 13(4), pp.319-340.

${ }^{*}$ Davis, R., Sajtos, L. and Chaudhri, A.A. (2011). "Do Consumers Trust Mobile Service Advertising?" Contemporary Management Research, 7(4), pp.245-270.

de Ruyter, K., Wetzels, M. and Kleijnen, M. (2001). "Customer Adoption of EService: An Experimental Study," International Journal of Service Industry Management, 12(2), pp.184-207.

DeLone, W.H. and McLean, E.R. (2003). "The DeLone and McLean Model of Information Systems Success: A Ten-Year Update," Journal of Mangement Information Systems, 19(4), pp.9-30.

Dinev, T. and Hart, P. (2006). "An Extended Privacy Calculus Model for ECommerce Transactions," Information Systems Research, 17(1), pp.61-80.

*Dinev, T., Bellotto, M., Russo, V., Seera, I. and Colautti, C. (2006). "Privacy Calculus Model in E-Commerce - A Study of Italy and the United States," European Journal of Information Systems, 15, pp.389-402.

Doney, P.M. and Cannon, J.P. (1997). "An Examination of the Nature of Trust in Buyer-Seller Relationships," Journal of Marketing, 61, pp.35-51.

Dong, X.L., Gabrlovich, E., Murphy, K., Dang, V., Horn, W., Lugaresi, C., Sun, S. and Zhang, W. (2015). "Knowledge-based Trust: Estimating the Trustworthiness of Web Sources," Proceedings of the VLDB Endowment.

Dowling, G. R. (1986). "Perceived Risk: The Concept and Its Measurement," Psychology and Marketing, 3, pp.193-210. 
*Eastlick, M.A. and Lotz, S. (2011). "Cognitive and Institutional Predictors of Initial Trust toward an Online Retailer," International Journal of Retail \& Distribution Management, 39(4), pp.234-255.

Egea, J.M.O. and Gonzalez, M.V.R. (2011). 'Explaining Physicians' Acceptance of EHCR Systems: An Extension of TAM with Trust and Risk Factors," Computers in Human Behavior, 27, pp.319-332.

*Eid, M. (2011). "Determinants of Ecommerce Customer Satisfaction, Trust, and Loyalty in Saudi Arabia," Journal of Electronic Commerce Research, 12(1), pp.78-93.

*Fang, Y.H., Chiu, C.M. and Wang, E.T.G. (2011). 'Understanding Customers' Satisfaction and Repurchase Intentions: An Integration of IS Success Model, Trust, and Justice," Internet Research, 21(4), pp.479503.

Featherman, M.S. and Pavlou, P.A. (2003). "Predicting E-Services Adoption: A Perceived Risk Facets Perspective," International Journal of HumanComputer Studies, 59, pp.451-474.

*Gefen, D. (2000). "E-Commerce: The Role of Familiarity and Trust," OMEGA, 28, 725-737.

${ }^{*}$ Gefen, D. (2002). "Customer Loyalty in ECommerce," Journal of the Association for Information Systems, 3, pp.27-51.

*Gefen, D., Karahanna, E. and Straub, D.W. (2003a). "Trust and TAM in Online Shopping: An Integrated Model," MIS Quarterly, 27(1), pp.51-90.

*Gefen, D., Karahanna, E. and Straub, D.W. (2003b). "Inexperience and Experience with Online Stores: The Importance of TAM and Trust," IEEE Transactions on Engineering Management, 50(3), pp.307-321.

*Gefen, D. and Straub, D.W. (2003). "Managing User Trust in B2C EServices," e-Service Journal, 2(2), pp.7-24.
Glass, G. V. (1976). "Primary, Secondary, and Meta-Analysis of Research," Educational Researcher, 5(9), pp.3-8.

Glover, S. ND Benbsat, I. (2011). "A Comprehensive Model of Perceived Risk of E-Commerce Transactions," International Journal of Electronic Commerce, 15(2), pp.47-78.

Grabner-Kräuter, S. and Kaluscha, E.A. (2003). "Empirical Research in OnLine Trust: A Review and Critical Assessment," International Journal of Human-Computer Studies, 58, pp.783-812.

${ }^{*}$ Gu, J.C., Lee, S.C. and Suh, Y.H. (2009). "Determinants of Behavioral Intention to Mobile Banking. Expert Systems with Applications, 36, pp.11605-11616.

Hagel, J. and Rayport, J. F. (1997). "The Coming Battle for Customer Information," Harvard Business Review, January-February, 5-11.

He, J., and King, W. (2008). "The Role of User Participation in Information Systems Development: Implications from a Meta-Analysis," Journal of Management Information Systems, 25(1), pp.301-331.

$\mathrm{He}$, J. (2011). "Understanding the Sources and Impacts of Trust in E-Commerce: A Meta-Analysis," Proceedings of the Seventeenth Americas Conference on Information Systems.

Hedges, L. and Olkin, I. (1985). Statistical Methods for Meta-Analysis. Academic Press, Orlando, FL.

${ }^{*} \mathrm{Ho}$, S.Y. and Chau, P.Y.K. (2013). "The Effects of Location Personalization on Integrity Trust and Integrity Distrust in Mobile Merchants," International Journal of Electronic Commerce, 17(4), pp.39-71.

Horst, M., Kuttschreuter, M. and Gutteling, J.M. (2007). "Perceived Usefulness, Personal Experiences, Risk Perception and Trust as Determinants of Adoption of EGovernment Services in the Netherlands," Computer in Human Behavior, 23, pp.1838-1852. 
*Hsieh, P.L. (2013). "Perceived Opportunism (PO) in E-Return Service Encounters," Managing Service Quality, 23(2), pp.96-110.

*Huang, L.T., Yin, K.L. and Farn, C.K. (2006). "Revisiting the Effectiveness of Institutional Antecedents in Building On-Line Initial Trust from the Perspective of Signal Theory," Journal of Global Business Management, 2(2), pp.85-96.

Hofstede, G., and Hofstede, G.J. (2005). Cultures and Organizations: Software of the Mind. New York: McGraw-Hill Professional.

Hunter, J.E. and Schmidt, F.L. (2004). Methods of Meta-Analysis Correcting Error and Bias in Research Findings. London, New Delhi, SAGE Publicantions.

Islam, A.K.M.N. and Mäntymäki, N. (2011). "Culture and Student Samples as Moderators of Continued IT Usage: A Meta-Analysis of IS Continuance Literature," Proceedings of the 2011 Pacific Asia Conference on Information Systems, paper 84.

Jarvenpaa, S. L., Tracinsky, N. and Vitale, M. (2000). "Consumer Trust in an Internet Store," Information Technology and Management, 1(1), pp.45-71.

*Johnson, D.S. (2007). "Achieving Customer Value from Electronic Channels through Identity Commitment, Calculative Commitment, and Trust in Technology," Journal of Interactive Marketing, 21(4), pp.1-22.

Joseph, D., Ng, K.Y., Koh, C. and Ang, S. (2007). "Turnover of Information Technology Professionals: A Narrative Review, Meta-Analytic Structural Equation Modeling, and Model Development," MIS Quarterly, 31(3), pp.547-577.

*Katos, V. (2012). "An Integrated Model for Online Transactions: Illuminating the Black Box," Information Management \& Computer Security, 20(3), pp.184-206.
*Kassim, N. and Abdullah, N.A. (2010). "The Effect of Perceived Service Quality Dimensions on Customer Satisfaction, Trust, and Loyalty in ECommerce Settings: A Cross Cultural Analysis," Asia Pacific Journal of Marketing and Logistics, 22(3), pp.351-371.

*Kassim, N.M. and Ismail, S. (2009). "Investigating the Complex Drivers of Loyalty in E-Commerce Settings," Measuring Business Excellence, 13(1), pp.56-71.

*Kesharwani, A. and Bisht, S.S. (2012). "The Impact of Trust and Perceived Risk on Internet Banking Adoption in India: An Extension of Technology Acceptance Model," International Journal of Bank Marketing, 30(4), pp.303-322.

*Klein, R. (2007). "Internet-Based PatientPhysician Electronic Communication Applications: Patient Acceptance and Trust," e-Service Journal, 5(2), pp.27-52.

Kim, D.J., Ferrin, D.L. and Rao, H.R. (2008). "A Trust-Based Consumer DecisionMaking Model in Electronic Commerce: The Role of Trust, Perceived Risk, and Their Antecedents," Decision Support Systems, 44(2), pp.544-564.

Kim, D.J., Ferrin, D.L. and Rao, H.R. (2009a). "Trust and Satisfaction, two Stepping Stones for Successful ECommerce Relationships: A Longitudinal Exploration," Information Systems Research, 20(2), pp.237-257.

Kim, G., Shin, B.S. and Lee, H.G. (2009b). "Understanding Dynamics between Initial Trust and Usage Intentions of Mobile Banking," Information Systems Journal, 19(3), pp.283-311.

${ }^{*} K i m$, S. and Park, H. (2013). "Effects of Various Characteristics of Social Commerce (S-Commerce) on Consumers' Trust and Trust Performance," International Journal of Information Management, 33, pp.318-332. 
King, W.R. and He, J. (2005). "Understanding the Role and Methods of Meta-Analysis in IS Research," Communications of the Association for Information Systems, 16, pp.665-686.

*Komiak, S.Y.X. and Benbasat, I. (2006). "The Effects of Personalization and Familiarity on Trust and Adoption of Recommendation Agents," MIS Quarterly, 30(4), pp.941-960.

Koufaris, M. and Hampton-Sosa, W. (2004). "The Development of Initial Trust in an Online Company by New Customers," Information and Management, 41(3), pp.377-397.

*Krasnova, H., Spiekermann, S., Koroleva, K. and Hildebrand, T. (2010). "Online Social Networks: Why We Disclose," Journal of Information Technology, 25, pp.109-125.

*Kuan, H.H. and Bock, G.W. (2007). "Trust Transference in Brick and Click Retailers: An Investigation of the Before-Online-Visit Phase," Information and Management, 44, pp.175-187.

Lee, T.M. (2005). "The Impact of Perceptions of Interactivity on Customer Trust and Transaction Intentions in Mobile Commerce," Journal of Electronic Commerce Research, 6(3), pp.165-180.

* Lee, J.K. and Rao, H.R. (2009). "Task Complexity and Different Decision Criteria for Online Service Acceptance: A Comparison of two EGovernment Compliance Service Domains," Decision Support Systems, 47, pp.424-435.

Lewis, W., Agarwal, R., and Sambamurthy, V. (2003). "Sources of Influence on Beliefs about Information Technology Use: An Empirical Study of Knowledge Workers," MIS Quarterly, 27(4), pp.657-678.

${ }^{*} \mathrm{Li}, \mathrm{R}$., Kim, J.J. and Park, J.S. (2007). "The Effects of Internet Shoppers' Trust on Their Purchasing Intention in China," Journal of Information
Systems and Technology Management, 4(3), pp.269-286.

${ }^{*} \mathrm{Li}, \mathrm{X}$., Hess, T.J. and Valacich, J.S. (2008). "Why Do We Trust New Technology?" A Study of Initial Trust Formation with Organizational Information Systems," Journal of Strategic Information Systems, 17, pp.39-71.

*Li, H., Gupta, A., Zhang, J. and Sarathy, R. (2013). "Examining the Decision to Use Standalone Personal Health Record Systems as a Trust-Enabled Fair Social Contract," Decision Support Systems, article in press.

Liang, T.P., Liu, C.C., and Wu, C.H. (2008). "Can Social Exchange Theory Explain Individual KnowledgeSharing Behavior? A Meta-Analysis," Proceedings of the Twenty-Ninth International Conference on Information Systems.

Liao, C., Liu, C. C. and Chen, K. (2011). "Examining the Impact of Privacy, Trust and Risk Perceptions beyond Monetary Transactions: An Integrated Model," Electronic Commerce Research and Applications, 10, pp.702-715.

Liberati, A., Altman, D. G., Tetzlaff, J., Mulrow, C., Gotzsche, P. C., loannidis, J. P. A., Clarke, M., Devereaus, P. J., Kleijnen, J., and Moher, D. (2009). "The PRISMA statement for reporting systematic reviews and meta-analysis of studies that evaluate health care interventions: explanation and elaboration," Journal of Clinical Epidemiology, 62, pp.e1-134.

*Lin, J., Lu, Y., Wang, B. and Wei, K.K. (2011). "The Role of Inter-channel Trust Transfer in Establishing Mobile Commerce Trust," Electronic Commerce Research and Applications, 10, pp.615-625.

Liu, C.C., Liang, T.P., Rajagopalan, B., Sambamurty, V., and Wu, J.C.H. (2011). "Knowledge, Sharing as Social Exchange: Evidence from a Meta-Analysis," Pacific Asia Journal 
of the Association for Information Systems, 3(4), pp.21-47.

*Liu, Z., Min, Q. and Ji, S. (2009). "An Empirical Study on Mobile Banking Adoption: The Role of Trust," Second International Symposium on Electronic Commerce and Security, pp.7-13.

*Lo, J. (2010). "Privacy Concern, Locus of Control, and Salience in a Trust-Risk Model of Information Disclosure on Social Networking Sites," AMCIS 2010 proceedings. Paper 110.

Lu, Y., Yang, S., Chau, P.Y.K. and Cao, Y. (2011). "Dynamics between the Trust Transfer Process and Intention to Use Mobile Payment Services: A Cross-Environment Perspective," Information and Management, 48, pp.393-403.

Lu, J. (2001). "Measuring Cost/Benefits of E-Business Applications and Customer Satisfaction," Proceedings of the 2nd International Web Conference, 29-30 November, Perth, Australia, pp.139-147.

*Luo, X., Li, H., Zhang, J. and Shim, J.P. (2010). "Examining MultiDimensional Trust and Multi-Faceted Risk in Initial Acceptance of Emerging Technologies: An Empirical Study of Mobile Banking Services," Decision Support Systems, 49(2), pp.222-234.

*Malhotra, N.K., Kim, S.S. and Agarwal, J. (2004). 'Internet Users' Information Privacy Concerns (IUIPC): The Construct, the Scale, and a Causal Model," Information Systems Research, 15(4), pp.336-355.

McKnight, D.H., Choudhury, V. and Kacmar, C. (2002). "The Impact of Initial Consumer Trust on Intentions to Transact with a Web Site: A Trust Building Model," Journal of Strategic Information Systems, 11, pp.297-323.

McKnight, D.H., Cummings, L.L. and Chervany, N.L. (1998). "Initial Trust Formation in New Organizational Relationships," The Academy of
Management Review, 23(3), pp.473490.

*McKnight, D.H., Kacmar, C.J. and Choudhury, V. (2004). "Shifting Factors and the Ineffectiveness of Third Party Assurance Seals: A TwoStage Model of Initial Trust in a Web Business," Electronic Markets, 14(3), pp.1-16.

Morgan, R.M. and Hunt, S. (1994). "The Commitment-Trust Theory of Relationship Marketing," Journal of Marketing, 58(1), pp.20-38.

Moody, G.D., Galletta, D.F. and Lowry, P.B. (2014). "When Trust and Distrust Collide Online: The Engenderment and Role of Consumer Ambivalence in Online Consumer Behavior," Electronic Commerce Research and Applications, 13, pp.266-282.

Mou, J. and Cohen, J.F. (2013). "Trust and Risk in Consumer Acceptance of EServices: A Meta-Analysis and a Test of Competing Models," Proceedings of the Thirty-Fourth International Conference on Information Systems.

Mou, J. and Cohen, J.F. (2014). "Trust, Risk Barriers and Health Beliefs in Consumer Acceptance of Online Health Services," Proceedings of the Thirty-Fifth International Conference on Information Systems.

Nicolaou A.I. and McKnight, D.H. (2006). "Perceived Information Quality in Data Exchanges: Effects on Risk, Trust, and Intention to Use," Information Systems Research, 17(4), pp.332-351.

*Pavlou, P.A. (2001). "Integrating Trust in Electronic Commerce with the Technology Acceptance Model: Model Development and Validation," Proceeding of Seventh Americas Conference on Information Systems, pp.816-822.

*Pavlou, P.A. (2003). "Consumer Acceptance of Electronic Commerce: Integrating Trust and Risk with the Technology Acceptance Model," 
International Journal of Electronic Commerce, 7(3), pp.101-134.

Pavlou, P.A. and Gefen, D. (2002). "Building Effective Online Marketplaces with Institution-Based Trust," Proceedings of the Twenty-Third International Conference on Information Systems, pp.667-675.

Pavlou, P.A. and Gefen, D. (2004). "Building Effective Online Marketplaces with Institution-Based Trust," Information Systems Research, 15(1), pp.37-59.

*Pavlou, P.A. and Gefen, D. (2005). "Psychological Contract Violation in Online Marketplaces: Antecedents, Consequences, and Moderating Role," Information Systems Research, 16(4), pp.372-399.

Petter, S., DeLone, W., and McLean, E.R. (2013). "Information Systems Success: The Quest for the Independent Variables," Journal of Management Information Systems, 29(4), pp. 7-61.

Petter, S. and McLean, E.R. (2008). "A Meta-analysis ssessment of the DeLone and McLean IS Success Model: An Examination of IS Success at the Individual Level," Information and Management, 46, pp.159-166.

*Pizzutti, C. and Fernandes, D. (2010). "Effect of Recovery Efforts on Consumer Trust nd Loyalty in E-tail: A Contingency Model," International Journal of Electronic Commerce, 14(4), pp.127-160.

*Qureshi, I., Fang, Y., Ramsey, E., McCole, P., Ibbotson, P. and Compeau, D. (2009). "Understanding Online Customer Repurchasing Intention and the Mediating Role of Trust - An Empirical Investigation in Two Developed Countries," European Journal of Information Systems, 18, pp.205-222.

${ }^{*}$ Ribbink, D., van Riel, A.C.R., Liljander, V. and Streukens, S. (2004). "Comfort Your Online Customer: Quality, Trust and Loyalty on the Internet,"
Managing Service Quality, 14(6), pp.446-456.

Rosenthal, R. (1979). "The 'File Drawer' Problem and Tolerance for Null Results," Psychological Bulletin, 86, pp.638-641.

Rotter, J.B. (1967). "A New Scale for the Measurement of Interpersonal Trust," Journal of Personality and Social Psychology, 35(4), pp.651665.

Rowley, J. (2006). "An Analysis of the EService Literature: Towards a Research Agenda," Internet Research, 16(3), pp.339-359.

Schepers, J. and Wetzels, M. (2007). "A Meta-Analysis of the Technology Acceptance Model: Investigating Subjective Norm and Moderation Effects," Information and Management, 44, pp.90-103.

*Shen, Y.C., Huang, C.Y., Chu, C.H. and Hsu, C.T. (2010). "A Benefit-Cost Perspective of the Consumer Adoption of the Mobile Banking System," Behaviour \& Information Technology, 29(5), pp.497-511.

Shao, R., Rupp, D.E., Skarlicki, D.P. and Jones, K.S. (2013). "Employee Justice Across Cultures: A MetaAnalysis Review," Journal of Management, 39(1), pp.263-301.

*Sia, C.L., Lim, K.H., Leung, K., Lee, M.K.O. and Huang, W.W. (2009). "Web Strategies to Promote Internet Shopping: Is Cultural-Customization Needed?" MIS Quarterly, 33(3), pp.491-512.

*Slyke, C.V., Shim, J.T., Johnson, R. and Jiang, J. (2006). "Concern for Information Privacy and Online Consumer Purchasing," Journal of the Association for Information Systems, 7(6), pp.415-444.

Srinivasn, S.S, Anderson, R. and Ponnavolu, K. (2002). "Customer Loyalty in ECommerce: An Exploration of Its Antecedents and Consequences," Journal of Retailing, 78, pp.41-50.

*Teh, P.L. and Ahmed, P.K. (2012). "Understanding Social Commerce 
Adoption: An Extension of the Technology Acceptance Model," Proceedings of the 2012 IEEE ICMIT, pp.359-364.

${ }^{*}$ Teo, T.S.H. and Liu, J. (2007). "Consumer Trust in E-Commerce in the United States, Singapore and China," OMEGA, 35, pp.22-38.

${ }^{*}$ Turel, O., Yuan, Y. and Connelly, C.E. (2008). "In Justice We Trust: Predicting User Acceptance of ECustomer Services," Journal of Management Information Systems, 24(4), pp.123-151.

Vassilakis, C., Lepouras, G., Fraser, J., Haston, S. and Georgiadis P. (2005). "Barriers to Electronic Service Development," e-Service Journal, 4(1), pp.41-65.

Walczuch, R. and Lundgren, H. (2004). "Psychological Antecedents of Institution-Based Consumer Trust in E-Retailing," Information and Management, 42, pp.159-177.

Wang, W. and Benbasat I. (2005). "Trust in and Adoption of Online Recommendation Agents," Journal of the Association for Information Systems, 6(3), pp.72-101.

Wareham, J., Zheng, J.G. and Straub, D. (2005). "Critical Themes in Electronic Commerce Research: A Meta-Analysis," Journal of Information Technology, 20, pp.1-19.

*Wen, C., Prybutok, V.R. and Xu, C. (2011). "An Integrated Model for Customer Online Repurchase Intention," The Journal of Computer Information Systems, 52(1), pp.14-23.

${ }^{*} X u, H .$, Teo, H.H. and Tan, B.C.Y. (2005a). "Predicting the Adoption of LocationBased Services the Role of Trust and Perceived Privacy Risk," Proceeding of Twenty-Sixth International Conference on Information Systems, pp.897-910.
*Xu, H., Wang, H. and Teo, H.H. (2005b). "Predicting the Usage of P2P Sharing Software: The Role of Trust and Perceived Risk," Proceedings of the 38th Hawaii International Conference on System Sciences.

"Yi, M.Y., Yoon, J.J., Davis, J.M. and Lee, T. (2013). "Untangling the Antecedents of Initial Trust in Web-Based Health Information: The Roles of Argument Quality, Source Expertise, and User Perceptions of Information Quality and Risk," Decision Support Systems, article in press.

Yousafzai, S.Y., Pallister, J.G. and Foxall, G.R. (2009). "Multi-Dimensional Role of Trust in Internet Banking Adoption," The Service Industries Journal, 29(5), pp.591-605.

Zahedi, F.M. and Song, J. (2008). "Dynamic of Trust Revision: Using Health Infomediaries," Journal of Management Information Systems, 24(4), pp.225-248.

*Zhou, T. (2011). "The Impact of Privacy Concern on User Adoption of Location-Based Services," Industrial Management \& Data Systems, 111(2), pp.212-226.

*Zhou, T. (2012). "Examining Mobile Banking User Adoption from the Perspectives of Trust and Flow Experience," Information Technology Management, 13, pp.27-37.

*Zhou, T. (2013). "An Empirical Examination of User Adoption of Location-based Services," Electronic Commerce Research, 13, pp.25-39.

*Zhu, D.S., Lee, Z.C. and O'Neal, G.S. (2011). "Mr. Risk! Please Trust Me: Trust Antecedents that Increase Online Consumer Purchase Intention," Journal of Internet Banking and Commerce, 16(3), pp.1-23. 
Pacific Asia Journal of the Association for Information Systems, Vol. 7, Iss. 1 [2015], Art. 2

Antecedents of Trust in Electronic-Service Providers: Results from a Meta-Analysis / Mou and Cohen

\section{Appendix}

Appendix A - Studies Used in Meta-Analysis

\begin{tabular}{|c|c|c|c|c|c|c|c|}
\hline Study & $\mathrm{P} / \mathrm{J}$ & Object & Coding & Population & Coding & Country & Coding \\
\hline Aldás-Manzano et al. (2009) & $\mathrm{J}$ & Internet Banking & $\mathrm{C}$ & Consumer & NS & Spanish & W \\
\hline Azam et al. (2013) & $\mathrm{J}$ & E-commerce & $\mathrm{C}$ & Student & $\mathrm{S}$ & China & $\mathrm{E}$ \\
\hline Bansal et al. (2010) & $\mathrm{J}$ & $\begin{array}{l}\text { Online Health } \\
\text { Information }\end{array}$ & $\mathrm{N}$ & Student & $\mathrm{S}$ & US & W \\
\hline Bhattacherjee (2002) & $\mathrm{J}$ & Online Firms & C & Consumer & NS & US & $\overline{\mathrm{W}}$ \\
\hline Casaló et al. (2011) & $\mathrm{J}$ & E-commerce & $\mathrm{C}$ & Consumer & NS & Spain & $\mathrm{W}$ \\
\hline Chang and Fang (2013) & $\mathrm{J}$ & Online Shopping & $\mathrm{C}$ & Consumer & NS & Taiwan & $\mathrm{E}$ \\
\hline Chellappa (2008) & $\mathrm{U}$ & E-commerce & $\mathrm{C}$ & Student & S & US & W \\
\hline Chen and Dibb (2010) & $\mathrm{J}$ & Online Retail & C & Student & $S$ & UK & W \\
\hline Chen and Teng (2013) & $\mathrm{J}$ & Online Store & C & Consumer & NS & Taiwan & $E$ \\
\hline Chiu et al. (2009) & $\mathrm{J}$ & Online Shopping & $\mathrm{C}$ & Consumer & NS & Taiwan & $\mathrm{E}$ \\
\hline Cho et al. (2007) & $\mathrm{P}$ & Internet Commerce & $\mathrm{C}$ & Student & $\mathrm{S}$ & Korea & $\mathrm{E}$ \\
\hline Chung and Shin (2010) & $\mathrm{J}$ & Internet Shopping & $\mathrm{C}$ & Student & $\mathrm{S}$ & Korea & $E$ \\
\hline Curry (2011) & $\mathrm{P}$ & Wi-Fi Hotspots & $\mathrm{N}$ & Student & $\mathrm{S}$ & US & $\mathrm{W}$ \\
\hline Davis et al. (2011) & $\mathrm{J}$ & $\begin{array}{l}\text { Mobile Service } \\
\text { Advertising }\end{array}$ & C & Consumer & NS & $\begin{array}{l}\text { New } \\
\text { Zealand }\end{array}$ & W \\
\hline Dinev et al. (2006) & $\mathrm{J}$ & E-commerce & $\mathrm{C}$ & Consumer & NS & Italy & W \\
\hline & & & & Consumer & NS & US & $\overline{\mathrm{W}}$ \\
\hline Eastlick and Lotz (2011) & $\mathrm{J}$ & Online Retailers & C & Consumer & NS & US & W \\
\hline Eid (2011) & $\mathrm{J}$ & E-commerce & C & $\begin{array}{l}\text { Student and } \\
\text { Workers }\end{array}$ & NS & Saudi Arabia & $\mathrm{E}$ \\
\hline Fang et al. (2011) & $\mathrm{J}$ & Online Shopping & $C$ & Consumer & NS & Taiwan & $E$ \\
\hline Gefen (2000) & $\mathrm{J}$ & E-commerce & $\mathrm{C}$ & Student & $\mathrm{S}$ & US & $\mathrm{W}$ \\
\hline Gefen (2002) & $\mathrm{J}$ & E-commerce & $\mathrm{C}$ & Student & $\mathrm{S}$ & US & $\mathrm{W}$ \\
\hline Gefen and Straub (2003) & $\mathrm{J}$ & B2C E-service & $\mathrm{C}$ & Student & $\mathrm{S}$ & US & $\mathrm{W}$ \\
\hline Gefen et al. (2003a) & $\mathrm{J}$ & Online Shopping & $\mathrm{C}$ & Student & $S$ & US & W \\
\hline Gefen et al. (2003b) & $\mathrm{J}$ & Online Stores & $\mathrm{C}$ & Student & $\mathrm{S}$ & US & W \\
\hline Gu et al. (2009) & $\mathrm{J}$ & Mobile Banking & C & Consumer & NS & Korea & $\mathrm{E}$ \\
\hline Hsieh (2013) & $\mathrm{J}$ & E-Return Service & C & Consumer & NS & Taiwan & $E$ \\
\hline Ho and Chau (2013) & $J$ & $\begin{array}{l}\text { Location-based } \\
\text { Services }\end{array}$ & $\mathrm{N}$ & Student & $S$ & $x$ & $X$ \\
\hline Huang et al. (2006) & $\mathrm{J}$ & E-commerce & $C$ & Student & $\mathrm{S}$ & Taiwan & $E$ \\
\hline Johnson (2007) & $\mathrm{J}$ & Banking Service & $\mathrm{C}$ & Consumer & NS & US & $\mathrm{W}$ \\
\hline Kassim and Abdullah (2010) & $\mathrm{J}$ & E-commerce & C & Consumer & NS & $\begin{array}{c}\text { Malaysia, } \\
\text { Qatar }\end{array}$ & $\mathrm{X}$ \\
\hline Kassim and Ismail (2009) & $\mathrm{J}$ & E-commerce & $\mathrm{C}$ & Consumer & NS & Qatar & $E$ \\
\hline Katos (2012) & $\mathrm{J}$ & Online Transition & $\mathrm{C}$ & Consumer & NS & Greece & $\mathrm{W}$ \\
\hline $\begin{array}{l}\text { Kesharwani and Bisht } \\
\text { (2012) }\end{array}$ & $\mathrm{J}$ & Internet Banking & C & Student & s & India & $\mathrm{E}$ \\
\hline Kim and Park (2013) & $\mathrm{J}$ & Social Commerce & $C$ & Consumer & NS & Korea & $\mathrm{E}$ \\
\hline Klein (2007) & $\mathrm{J}$ & E-health & $\mathrm{N}$ & Consumer & NS & US & $\bar{W}$ \\
\hline $\begin{array}{l}\text { Komiak and Benbasat } \\
\qquad(2006)\end{array}$ & $\mathrm{J}$ & $\begin{array}{c}\text { Web-Based } \\
\text { Recommendation } \\
\text { Agents }\end{array}$ & C & Student & $s$ & Canada & W \\
\hline Krasnova et al. (2010) & $\mathrm{J}$ & Social Networks & $\mathrm{N}$ & Student & $\mathrm{S}$ & Germany & $\mathrm{W}$ \\
\hline Kuan and Bock (2007) & $\mathrm{J}$ & $\begin{array}{c}\text { Online Shopping } \\
\text { Intention }\end{array}$ & C & Consumer & NS & $\begin{array}{c}\text { Singapore or } \\
\text { Korea }\end{array}$ & $\mathrm{E}$ \\
\hline Lee and Rao (2009) & $\mathrm{J}$ & E-government & $\mathrm{N}$ & Student & $\mathrm{S}$ & US & $\mathrm{W}$ \\
\hline Li et al. (2008) & $\mathrm{J}$ & New Technology & $\mathrm{N}$ & Student & $\mathrm{s}$ & US & W \\
\hline Li et al. (2013) & $\mathrm{J}$ & $\begin{array}{l}\text { Health Record } \\
\text { Systems }\end{array}$ & $\mathrm{N}$ & Student & S & US & W \\
\hline Li et al. (2007) & $\mathrm{J}$ & Internet Shopping & $\mathrm{C}$ & Student & $\mathrm{S}$ & China & $\mathrm{E}$ \\
\hline Lin et al. (2011) & $\mathrm{J}$ & Mobile Commerce & $\mathrm{C}$ & Consumer & NS & China & $E$ \\
\hline Liu et al. (2009) & $\mathrm{P}$ & Mobile Banking & $\mathrm{C}$ & Consumer & NS & China & $\mathrm{E}$ \\
\hline
\end{tabular}




\begin{tabular}{|c|c|c|c|c|c|c|c|}
\hline Luo et al. (2010) & $\mathrm{J}$ & Mobile Banking & $C$ & Student & $\mathrm{S}$ & US & $\mathrm{W}$ \\
\hline Lo $(2010)$ & $\mathrm{P}$ & Social Networks & $\mathrm{N}$ & Student & $\mathrm{S}$ & US & $\mathrm{W}$ \\
\hline Malhotra et al. (2004) & $\mathrm{J}$ & Internet & $\mathrm{N}$ & Consumer & NS & US & $\mathrm{W}$ \\
\hline McKnight et al. (2004) & $\mathrm{J}$ & Web Business & $\mathrm{C}$ & Student & $\mathrm{S}$ & US & $\overline{\mathrm{W}}$ \\
\hline Pavlou (2001) & $\mathrm{P}$ & E-commerce & $\mathrm{C}$ & Student & $\mathrm{S}$ & US & $\overline{\mathrm{W}}$ \\
\hline Pavlou (2003) & $\mathrm{J}$ & E-commerce & $\mathrm{C}$ & Consumer & NS & US & $\overline{\mathrm{W}}$ \\
\hline Pavlou and Gefen (2005) & $\mathrm{J}$ & Online Marketplaces & C & Consumer & NS & US & W \\
\hline $\begin{array}{l}\text { Pizzutti nd Fernandes } \\
(2010)\end{array}$ & $\mathrm{J}$ & E-tail & C & Consumer & NS & Brazil & W \\
\hline \multirow[t]{2}{*}{ Qureshi et al. (2009) } & $\mathrm{J}$ & Online Shopping & C & Student & $\mathrm{s}$ & $\begin{array}{c}\text { New } \\
\text { Zealand }\end{array}$ & W \\
\hline & & & & $\begin{array}{l}\text { Student and } \\
\text { Staff }\end{array}$ & NS & $\begin{array}{l}\text { Northern } \\
\text { Ireland }\end{array}$ & W \\
\hline Ribbink et al. (2004) & $\mathrm{J}$ & E-commerce & C & Consumer & NS & European & W \\
\hline Shen et al. (2010) & $\mathrm{J}$ & Mobile Banking & $\mathrm{C}$ & Consumer & NS & Taiwan & $E$ \\
\hline Sia et al. (2009) & $\mathrm{J}$ & Internet Shopping & $\mathrm{C}$ & Student & $\mathrm{S}$ & Australia & $\mathrm{W}$ \\
\hline Slyke et al. (2006) & $\mathrm{J}$ & Online Purchasing & C & Student & $\mathrm{S}$ & US & W \\
\hline Teh and Ahmed (2012) & $\mathrm{P}$ & Social Commerce & $C$ & Student & $\mathrm{s}$ & Malaysia & $E$ \\
\hline \multirow[t]{3}{*}{ Teo and Liu (2007) } & $\mathrm{J}$ & E-commerce & $C$ & Student & $\mathrm{S}$ & US & $\overline{\mathrm{W}}$ \\
\hline & & & & Student & $S$ & Singapore & $E$ \\
\hline & & & & Student & $\mathrm{s}$ & China & $E$ \\
\hline Turel et al. (2008) & $\mathrm{J}$ & E-customer Services & $C$ & Student & $\mathrm{S}$ & US & $\bar{W}$ \\
\hline Wen et al. (2011) & $\mathrm{J}$ & Online Shopping & $\mathrm{C}$ & Student & $\mathrm{S}$ & US & $\overline{\mathrm{W}}$ \\
\hline Xu et al. (2005a) & $\mathrm{P}$ & $\begin{array}{c}\text { Location-based } \\
\text { Services }\end{array}$ & $\mathrm{N}$ & Consumer & NS & Singapore & E \\
\hline Xu et al. (2005b) & $P$ & $\begin{array}{l}\text { P2P Information } \\
\text { Sharing }\end{array}$ & $\mathrm{N}$ & Student & $\mathrm{s}$ & Singapore & $\mathrm{E}$ \\
\hline Yi et al. (2013) & $\mathrm{J}$ & $\begin{array}{l}\text { Web-based Health } \\
\text { Information }\end{array}$ & $\mathrm{N}$ & Consumer & NS & Korea & $\mathrm{E}$ \\
\hline Zhou (2012) & $\mathrm{J}$ & Mobile Banking & C & Consumer & NS & China & $\mathrm{E}$ \\
\hline Zhou (2011) & $\mathrm{J}$ & $\begin{array}{l}\text { Location-based } \\
\text { Services }\end{array}$ & $\mathrm{N}$ & Student & S & China & $E$ \\
\hline Zhou (2013) & $\mathrm{J}$ & $\begin{array}{l}\text { Location-based } \\
\text { Services }\end{array}$ & $\mathrm{N}$ & Student & S & China & $E$ \\
\hline Zhu et al. (2011) & $\mathrm{J}$ & Online Shopping & $C$ & Student & $\mathrm{s}$ & Taiwan & $E$ \\
\hline
\end{tabular}

Notes: P: Proceeding; J: Journal; U: Un-published paper; C: Commercial; N: Non-commercial; S: Student; NS: Non-student; W: Western; E: Eastern; X: Non-specified.

\section{About the authors}

Jian Mou completed his PhD degree in Information Systems at the University of the Witwatersrand, Johannesburg, South Africa. Jian Mou holds a Master's Degree in Management Information Systems from Pusan National University, South Korea. His research interests include digital services, trust and risk issues in electronic services, and the dynamic nature in systems use. His research has been published in the proceedings of International Conference on Information Systems (2013, 2014), Pacific Asia Conference on Information Systems (2014), as well as Australasian Conference on Information Systems.
Jason Cohen is an Associate Professor of Information Systems in the School of Economic and Business Sciences at the University of the Witwatersrand, Johannesburg. He received his $\mathrm{PhD}$ in Information Systems in 2004 with a focus on IS strategy and planning. His research work is focused on IT in services. His work has been published in journals such as Information \& Management, International Journal of Information Management, Expert Systems with Applications, International Journal of Hospitality Management, and Journal of Information Systems Education. 